\title{
Adaptive evolution of butterfly wing shape: from morphology to behaviour
}

\author{
Camille Le Roy ${ }^{1,2, *}$, Vincent Debat ${ }^{1, \dagger}$ and Violaine Llaurens ${ }^{1, \dagger}$ \\ ${ }^{1}$ Institut de Systématique, Evolution et Biodiversité (ISYEB), Muséum National d'Histoire \\ Naturelle, CNRS, Sorbonne Université, EPHE, 57 rue Cuvier CP50, 75005, Paris, France \\ ${ }^{2}$ Université Paris Descartes, Sorbonne Paris Cité, Paris, France
}

*Author for correspondence (E-mail: leroy.camille7@gmail.com; Tel: +33 1407937 73).

$\dagger$ Authors contributed equally and are listed in alphabetical order.

\begin{abstract}
Butterflies display extreme variation in wing shape associated with tremendous ecological diversity. Disentangling the role of neutral versus adaptive processes in wing shape diversification remains a challenge for evolutionary biologists. Ascertaining how natural selection influences wing shape evolution requires both functional studies linking morphology to flight performance, and ecological investigations linking performance in the wild with fitness. However, direct links between morphological variation and fitness have rarely been established. The functional morphology of butterfly flight has been investigated but selective forces acting on flight behaviour and associated wing shape have received less attention. Here, we attempt to estimate the ecological relevance of morpho-functional links established through biomechanical studies in order to understand the evolution of butterfly wing morphology. We survey the evidence for natural and sexual selection driving wing shape evolution in butterflies, and discuss how our functional knowledge may allow identification of the selective forces involved, at both the macro- and micro-evolutionary scales. Our review shows that although correlations between wing shape variation and ecological factors have been established at the macro-evolutionary level, the underlying selective pressures often remain unclear. We identify the need to investigate flight behaviour in relevant ecological contexts to detect variation in fitness-related traits. Identifying the selective regime then should guide experimental studies towards the relevant estimates of flight performance. Habitat, predators and sex-specific behaviours are likely to be major selective forces acting on wing shape evolution in butterflies. Some striking cases of morphological divergence driven by contrasting ecology involve both wing and body morphology, indicating that their interactions should be included in future studies investigating co-evolution between morphology and flight behaviour.
\end{abstract}

Key words: Lepidoptera, diversification, wing morphology, flight behaviour, aerodynamic performance, coevolution, fitness. 


\section{CONTENTS}

I. Introduction

II. How does morphological variation affect flight performance?

(1) Gliding flight

(2) Flapping flight

(3) Roles of the forewings and hindwings during flight

(4) Body-wing interactions

(5) Manoeuvrability and agility

(6) Fine-scale shape variations

(7) Three-dimensional wing shape

III. Flight measurements and behavioural characterization

(1) Methods of flight quantification: what do laboratory analyses tell us about natural behaviours?

(2) Flight kinematics as a measure of flight behaviour diversity

IV. What selective factors influence flight and associated wing morphology?

(1) Microhabitat

(2) Predation

(3) Morpho-behavioural convergence: when mimicry goes beyond colour pattern

(4) Long-distance flight in response to fluctuating environments

(5) Sex-specific behaviours

(6) Sexual selection

V. Conclusions

VI. Acknowledgments

VII. References 


\section{INTRODUCTION}

Studies on morphological evolution generally focus on the role of adaptation and face two main challenges: first, devising neutral expectations for complex traits is not straightforward, and second, precisely estimating the effect of morphological changes on fitness is difficult.

Morphological variation is usually studied at the macro-evolutionary scale using phylogenetic comparative methods: departure from neutral divergence along tree branches implies putative adaptive evolution (e.g. Cespedes, Penz \& DeVries, 2015; Chazot et al., 2016; Penz \& Heine, 2016). Within species, comparing morphological divergence with neutral divergence at molecular loci $\left(F_{\mathrm{ST}} / Q_{\mathrm{ST}}\right.$ studies) enables the detection of adaptive microevolution (Koskinen, Haugen \& Primmer, 2002; Leinonen et al., 2013; Schäfer et al., 2018). Deviations from neutral expectations, however, remain insufficient to ascertain the contribution of selection to morphological divergence. They nevertheless lead to the formulation of hypotheses on the selection regime involved, driven by ecological context, and allow the development of experimental tests on the effect of morphological variation on individual fitness. This often requires studying the consequences of morphological variation on performance and its impact on an individual's ability to perform fitness-related behaviours (e.g. escape from predators or mating) (Bonine \& Garland, 1999; Garland \& Losos, 1994; Wainwright, 1991). Morphology imposes limits on behavioural capabilities (i.e. performance), which in turn constrains realized behaviour (Fig. 1). For example, wing morphology in butterflies sets limits on flight manoeuvrability, which might constrain escape behaviour. Behaviour is however more plastic than morphology (West-Eberhard, 1989), allowing some compensation for morphological differences. Insects with damaged wings, for example, can compensate for the reduced lift through changes in body and wing kinematics (Fernández, Springthorpe \& Hedrick, 2012; Muijres et al., 2017). Nevertheless, natural selection acting on flight behaviour is also likely to result in adaptive changes in morphology: fitness peaks differing between species or populations will then generate divergent morphological and behavioural evolution, likely involving suites of interacting traits (e.g. wing morphology, colour pattern and body size). Links between morphological variation and associated behaviours have been investigated using studies of functional and ecological morphology [i.e. ecomorphology (see Arnold, 1983; Garland \& Losos, 1994; Kingsolver \& Huey, 2003; Wainwright \& Reilly, 1994)].

The evolution of flight-related traits has been comprehensively studied using ecomorphological approaches in vertebrates (Norberg, 2012; Norberg \& Rayner, 1987; Rayner, 1988; Tanalgo et al., 2012), providing general predictions for the link between wing shape and flying capacities in different environments. In insects however, while the functional morphology of flight has received much attention (Dudley, 1990; 2002; Ellington, 1984b; Sane, 2003; Wang, 2005; Wootton, 1990, 1992), relatively little is known regarding the selective pressures acting on flight and associated wing shape (Betts \& Wootton, 1988; Outomuro et al., 2016).

Among flying insects - and perhaps all flying animals - butterflies possess the largest wing area relative to body mass (Ellington, 1984f). Their two highly developed wing pairs and typical flap-gliding flight distinguish them from other flying insects. Butterfly wings are covered by scales, and are frequently coloured due to pigments and/or micro/nanostructures (Debat et al., 2018; Ghiradella et al., 1972; Vukusic, Sambles \& Lawrence, 2000), resulting in a tremendous diversity of colour patterns. The evolution of these diverse colour patterns is likely to interact with the evolution of wing shape and size. In contrast to our extensive knowledge of butterfly wing colour-pattern development and evolution (e.g. Merrill et al., 2015; Nijhout, 1991; Zhang et al., 2017), the evolution of butterfly wing shape has received considerably less attention. Yet, butterflies display an extreme diversity of wing sizes and shapes associated with their tremendous ecological diversity. For example, some species 
migrate across continents and natural selection may therefore have promoted wing shapes that minimize the cost of long-distance flight (Altizer \& Davis, 2010). Within habitats, species can be segregated either spatially (e.g. between the canopy and understorey) (DeVries, Penz \& Hill, 2010), or temporally (e.g. with different activity peaks during the day) (Penz \& Heine, 2016). Spatial and temporal niches are characterized by differences in abiotic (temperature, light) and biotic (plant and predator community) environments, exerting contrasting selective pressures on flight behaviour. Some butterflies can escape predators because of their great agility and/or flight speed, while others are protected by their wing colour pattern, whether aposematic (Sherratt \& Beatty, 2003) or cryptic (Suzuki, Tomita \& Sezutsu, 2014). While colour pattern is known to play a role in mate choice (Robertson \& Monteiro, 2005), wing shape likely also contributes to sexual selection as many butterflies perform complicated flight manoeuvres during courtship (Scott, 1973). Variation in mate-locating strategies among male butterflies may also require contrasting flight performance, driving divergence in wing morphology within species (Berwaerts, Aerts \& Van Dyck, 2006; Van Dyck, Matthysen \& Dhondt, 1997). Butterfly wing shape and colour thus are directly involved in various fitnessrelated behaviours, potentially providing a model to investigate how selective forces drive morphological evolution. Phylogenetic relationships are moreover well resolved for many taxa (Barber et al., 2015; Braby, Vila \& Pierce, 2006; Espeland et al., 2018; Kristensen, Scoble \& Karsholt, 2007; Penz \& DeVries, 2002). Reliable phylogenies allow the investigation of macro-evolutionary processes acting on wing shape through comparative studies (e.g. Chazot et al., 2016; Penz \& Heine, 2016). Estimating the influence of morphological variation among species on flight performance is challenging, particularly because of interactions with other traits that also diverge among species (but see Tercel, Veronesi \& Pope, 2018). By contrast, studies conducted at the population level have allowed demonstrations of how flight performance relates to behaviour and fitness [e.g. in Danaus plexippus (Altizer \& Davis, 2010) and Pararge aegeria (Berwaerts, Van Dyck \& Aerts, 2002; Berwaerts et al., 2006; Berwaerts, Matthysen \& Van Dyck, 2008; Hughes, Hill \& Dytham, 2003)].

The general goal of this review is to assess the importance of adaptive processes in the diversification of butterfly wing morphology and associated flight behaviours. We first review current knowledge on flight performance associated with different wing morphologies, highlighting the remarkable complexity of insect flight. We specifically discuss the morphofunctional links established through biomechanical studies, and estimate their relevance to understanding the evolution of flight behaviour and morphology in butterflies. Second, we review the methods used to characterize flight behaviour in controlled and natural environments. Finally, we report the documented associations between wing shape and environmental/ecological variables and discuss how our functional knowledge may help us to understand adaptive processes at both the macro- and micro-evolutionary scales. 


\section{HOW DOES MORPHOLOGICAL VARIATION AFFECT FLIGHT PERFORMANCE?}

We here present an overview of the morphological parameters known to affect insect flight performance, with an emphasis on butterfly flight.

There is a large body of literature investigating the flight of insects, partly driven by applied research on biomimicry [e.g. the development of bioinspired micro-air-vehicles (Floreano \& Wood, 2015; Liu et al., 2016)]. Although anchored in biomechanics and not driven by evolutionary questions, it provides useful predictions on the links between wing morphology, kinematics and flight behaviour. Linking wing morphology to fitness indeed requires studying the effects of morphological variation on flight performance.

Flight is biomechanically defined as any locomotor behaviour in the air involving active control of aerodynamic forces (Dudley et al., 2007). Lift and drag forces can be regulated by behaviour through changes in wing orientation and movement. The typical gliding and flapping phases observed in butterfly flight lead to different aerodynamic expectations. During equilibrium gliding (i.e. when postural adjustments are omitted), a constant speed and orientation can be assumed, so that lift and drag forces do not vary with time (steady-state conditions). By contrast, flapping flight involves active wingbeats with extensive variation in wing velocity and orientation. The forces generated by air flow interacting with the wing vary greatly with time (unsteady conditions) (Dudley, 2002). Specific flight behaviours like takeoff, climbing, or complex manoeuvres rely on the use of the unsteady flow induced by flapping wings. Estimating the aerodynamic forces involved is thus more difficult for flapping than for gliding flight, limiting our capacity to predict the effect of morphological variation on flapping performance using simple aerodynamic models. Although butterfly flight is generally composed of a series of alternating flapping and gliding phases, predicting the aerodynamic consequences of wing shape variation is usually carried out separately for gliding and flapping sequences. Below, we review general predictions for the association between wing shape and flight performance, highlighting the importance of choosing an estimate of flight performance relevant to the hypothetical selective regime.

\section{(1) Gliding flight}

Gliding flight is widespread in butterflies (Kingsolver \& Koehl, 1985), although the proportion of gliding to flapping phases varies extensively among species (Altizer \& Davis, 2010; DeVries et al., 2010). The use of gliding flight greatly limits metabolic costs relative to powered flight, and may thus be advantageous in species that fly large distances, promoting wing morphologies that maximize gliding performance. Engineers seeking to optimize the energy budget of gliding devices have studied the aerodynamic consequences of wing shape variation (e.g. Park et al., 2010) and highlighted the key role of wing aspect ratio $(A R)$, computed as the ratio of wingspan to mean wing width (i.e. chord). A high- $A R$ characterizes long and narrow wings, whereas low- $A R$ wings are short and broad (Fig. 2A). At a constant velocity and orientation (assumed in equilibrium gliding), a high- $A R$ wing reduces the magnitude of wing-tip vortices (i.e. yielded airflow inherent to lift production), thus reducing the drag induced by these vortices, and the energy required to overcome this drag (Dudley, 2002; Vogel, 1994) (Fig. 2A). High-AR wings allow gliding for a longer distance relative to height lost (i.e. minimizing the glide angle). The glide angle is inversely related to the lift-todrag ratio: the smaller the glide angle, the higher this ratio, and the better the gliding performance (Ennos, 1989).

Using numerical simulations and wind-tunnel experiments, Ancel et al. (2017) compared the lift-to-drag ratio for four butterfly wing models (Fig. 3A) with different shapes. As expected theoretically, higher values were associated with the highest $A R$. They also showed that gliding performance increased when the wing orientation maximized wing span. Butterfly 
wing shape can be modified behaviourally by adjusting the position of the wings during a glide, inducing changes in aerodynamic forces as observed in gliding birds (Lentink et al., 2007). Field observations generally agree with expectations based on wing morphology: a high $A R$ is often associated with longer periods of gliding in butterflies (Betts \& Wootton, 1988; DeVries et al., 2010). That a reduced flight cost will accompany a high $A R$ has been empirically validated in birds (Ricklefs, Konarzewski \& Daan, 1996): estimates of flight metabolism for species with extremely high $A R$ such as performance-gliders like swifts (Lentink \& de Kat, 2014) shows that energy expenditure during flight is low compared to species of similar size but smaller $A R$ (Hails, 1979). Similar biomechanical predictions can be made for butterflies (Cespedes et al., 2015; DeVries et al., 2010; Jones et al., 2013), but have not yet been experimentally quantified.

Measurements of $A R$ have been suggested to be inadequate to describe the complex shape of butterfly wings (Betts \& Wootton, 1988; Ennos, 1989). For instance, very wide wings with a low $A R$ may still have a pointed wing tip (such as a triangular wing), reducing the drag associated with wing-tip vortices and therefore improving gliding performance. Measurements focusing on wing-tip shape rather than the overall wing plan used to describe vertebrate wings (Lockwood, Swaddle \& Rayner, 1998; Norberg \& Rayner, 1987) may be more relevant to gliding flight in butterflies. Other morphological parameters, such as the second moment of wing area, which estimates the distribution of area along the wing axis, are more relevant to flapping flight, and are discussed in Section II.2.

Other aspects of morphology are known to influence gliding ability. Forked tails in swallows increase the lift to drag ratio and improve stability during gliding flight (Balmford, Thomas \& Jones, 1993; Thomas \& Balmford, 1995). The presence of hindwing tails in swallowtail butterflies has been shown to have similar aerodynamic consequences using a model tested in a wind-tunnel (Park et al., 2010). Including the presence/absence and shape of hindwing tails in comparative studies of butterfly flight might thus improve our understanding of gliding flight performance and associated morphology.

Because butterflies switch from gliding to flapping flight, the evolution of wing morphology might result from a trade-off between performance in these two flight modes (see Section II.2).

\section{(2) Flapping flight}

Flapping flight is energetically costly relative to gliding flight but enables crucial behaviours like take-off, hovering, climbing, and the execution of complex manoeuvres. Despite its ecological significance, the aerodynamic properties of flapping flight are poorly known (Chin \& Lentink, 2016), probably because this flight mode does not meet the general assumptions used in aeronautics. Flapping wings generate unsteady conditions: lift and drag forces vary during the wingbeat, limiting the application of classical aerodynamic models (Dudley, 2002).

To apply such models, instantaneous forces on a flapping wing can be calculated independently from previous movements, to allow forces to be predicted using instantaneous kinematic parameters such as velocity, acceleration and orientation of the wing. Such 'quasisteady’ models (see Chin \& Lentink, 2016; Ellington, 1984a; Sane, 2003) allow aerodynamic forces to be estimated when both morphological and wingbeat kinematics data are available (e.g. Dudley, 1991; Ray et al., 2016; Sane \& Dickinson, 2002; Willmott \& Ellington, 1997b). Ellington's (1984a,b,c,d,e) seminal work on various insects demonstrated the effect of wing shape on the aerodynamic forces generated by flapping wings using a quasi-steady model, and in particular the relevance of moments of wing area to infer flapping flight efficiency. Moments of wing area describe the distribution of area along the wingspan and are linked to wing rotation around the body axis during the wingbeat (Fig. 2B). Because the wing tip moves faster than the wing base, the distribution of area along the wing will strongly influence the aerodynamic forces produced. Wings with a high moment of area (i.e. with a 
large fraction of wing area located distally) produce higher aerodynamic forces during a wingbeat. The second moment of area is especially informative regarding lift force [see Ellington (1984b) for formulae; Muijres et al., 2017].

However, the quasi-steady analysis has been shown to be inadequate to explain the lift required to compensate insect weight (Dudley, 1991; Ennos, 1989; Zanker \& Götz, 1990). Unsteady mechanisms are necessary to account for the observed lift, which mainly arises from vortices produced during the wing stroke and additional circulation built up by dorsal contact between the wings (Birch \& Dickinson, 2003; Srygley \& Thomas, 2002; Weis-Fogh, 1973) (see Fig. 3C). Various unsteady mechanisms have been observed in butterflies to interact during successive wing strokes (Srygley \& Thomas, 2002). Identifying how morphological variation in the wing (shape, vein architecture or flexibility) might affect the efficiency of such unsteady mechanisms remains a challenge, but would help us to understand wing evolution. A recent focus on the aerodynamic consequences of wing shape variation in the fruit fly Drosophila hydei has considered the effect of unsteady mechanisms using a robotic wing (Muijres et al., 2017): large variations in the second moment of wing area due to simulated wing damage resulted in changes in the measured aerodynamic forces. These results indicated that the quasi-steady approach remains relevant, and validates the use of moments of area by evolutionary biologists to infer flapping efficiency from wing shape variation in butterflies (Cespedes et al., 2015; DeVries et al., 2010; Jones et al., 2013; Mendoza-Cuenca \& Macías-Ordóñez, 2005; Penz \& DeVries, 2002).

Moments of area and $A R$ can be used to estimate potential trade-offs between flapping and gliding performance associated with different wing shapes. For example, Papilionidae tend to have a large $A R$ and a low moment of area, suggesting better gliding performance, whereas Lycaenidae have a lower $A R$ and relatively high moment of area suggesting better performance in flapping flight (Fig. 4). However, some groups do not show this pattern: for instance, most Hesperiidae have a high $A R$ combined with relatively large moments of area. The widely diversified family Nymphalidae show a large range in $A R$ and moments of area (Fig. 4), preventing general conclusions on a putative gliding/flapping trade-off. More studies investigating flight behaviour among butterfly species, focusing in particular on their relative use of gliding and flapping flight, could help to clarify how this may relate to wing shape variation.

\section{(3) Roles of the forewings and hindwings during flight}

Different roles of the fore- and hindwings in flight behaviours have been documented in many insects, suggesting that different selective regimes may act on fore- and hindwing evolution (Dudley, 2002). Some insects predominantly use their forewings during flight (i.e. anteromotoric flight) and have comparatively smaller hindwings (e.g. Hymenoptera), while others have enlarged hindwings and use posteromotoric flight (e.g. Orthoptera) (Brodsky, 1994). Butterflies are mostly anteromotoric flyers but nevertheless possess two highly developed wing pairs (Wootton, 1992). During gliding flight, the two wing pairs overlap to form a continuous aerodynamic surface. Fore- and hindwing shape is thus generally considered as a single wing planform when investigating the effect of wing shape variation on gliding performance (e.g. Ancel et al., 2017; Park et al., 2010). During flapping flight, the two wing pairs of butterflies beat synchronously with the forewing partially overlapping the hindwing. The extent of overlap may vary during the wingbeat as there is generally no mechanical connection between the two wing pairs. In some moths, however, the fore and hindwings are physically coupled by a set of fused hair-like scales (Braun, 1924; Tillyard, 1918), the hindwings may be significantly reduced in size (e.g. Sphingidae, Sesiidae, Arctiidae), and the coupled wings are moved at a relatively high wingbeat frequency (Dudley, 2002). This stands in sharp contrast to other butterflies and moths which tend to have partially decoupled movements of similarly sized fore- and hindwings (Grodnitskii \& Kozlov, 1985). 
That the two wing pairs of butterflies and moths have different roles in flight is clear: while removal of the forewings renders butterflies flightless, ablation of the hindwings causes significant reduction in linear and turning acceleration (Jantzen \& Eisner, 2008). The action of the forewings essentially drives butterfly flight, while the hindwings serve both as an extended airfoil during gliding flight, and to provide additional power during rapid manoeuvres in flapping flight. Understanding the different roles of each wing pair in flight performance is thus essential to understanding the evolution of their morphologies.

\section{(4) Body-wing interactions}

Interactions between wing area and body mass also affect flight performance (Ennos, 1989). Wing loading $(W L)$, i.e. body mass relative to wing area, has been shown to affect flight performance in butterflies (e.g. Berwaerts et al., 2002). Wings generate lift due to the flow of air over the wing surface. For a given body mass larger wings move more air, so that low $W L$ provides more lift at any given speed. Animals with low WL can fly slowly and still produce the necessary lift, whereas heavier flying animals need to fly faster. Experimental studies on butterfly flight have shown a positive association between flight speed and WL (Betts \& Wootton, 1988; Chai \& Srygley, 1990; Dempster, King \& Lakhani, 1976; Dudley, 1990, Dudley \& Srygley, 1994), as previously found for vertebrate flight (Norberg \& Rayner, 1987; Rayner, 1988).

More precise predictions can be drawn from $W L$, for both gliding and flapping flight: in equilibrium gliding (i.e. moving at a constant airspeed and glide angle), flight speed is proportional to the square root of $W L$ (Norberg, 1990). In flapping flight, larger force production is required for high-WL animals, who thus use a higher wingbeat frequency (Ahmad, 1984; Byrne, Buchmann \& Spangler, 1988). Finer predictions of flight performance can be made considering the relationship between $A R$ and $W L$ (Fig. 5). A combination of high $A R$ and low WL (top left on Fig. 5) allows slow, inexpensive flight. By contrast, high $A R$ and $W L$ (top right on Fig. 5) are often associated with fast flight. These variations can be even more extreme, with emblematic examples such as the long-winged giant African swallowtail butterfly (Papilio antimachus) displaying extensive gliding (Sáfián, 2013) on one hand, and sphingid moths belonging to the fastest flying insects on the other hand (Stevenson et al., 1995).

Flight performance depends not only on wing dimensions, but also on physiological properties: muscle contractions powering wing movements are energetically costly. Muscular power is linked to muscle mass and by extension to body weight (Dudley, 1990). Butterflies with high $W L$ frequently possess a greater proportion of muscle mass, allowing powerful flight (Berwaerts et al., 2002). Such morphologies involve a high cost of flight and limit the capacity for slow flight because a sufficient flight speed is required to generate lift. In a large sample of moth species, oxygen consumption during flight was shown to increase with thoracic mass and WL (Bartholomew \& Casey, 1978). The larger amount of energy required for flight in heavy flyers may thus limit flight duration compared to lower $W L$ slower flyers.

The minimum energy required to fly, just like maximum flight speed, is another metric of flight performance because it represents the limit imposed by morpho-physiological traits. However, there are strong trade-offs between these two flight performance components (Chai \& Srygley, 1990; Dudley, 2002; Norberg, 2002): wing morphologies associated with low energy expenditure mainly involve slow gliding flight, whereas wings enabling rapid powerful flight are most often associated with active, energetically costly flapping flight.

\section{(5) Manoeuvrability and agility}

Escaping predators, avoiding obstacles or performing acrobatic sexual displays depends on the ability to perform complex flight manoeuvres. Previous studies focusing mostly on vertebrates have generated predictions of the effects of wing morphology on manoeuvrability. 
Manoeuvrability can be defined as the space required to alter the flight trajectory while flying at a fixed speed, and can be estimated as the minimum angle of turn (Rayner, 1988). Turning angle generally increases with body mass and wing loading (Pennycuick, 1975). Manoeuvrability is therefore expected to be higher for low WL animals, as observed in bats (Aldridge, 1987). Comparisons of flight kinematics across butterflies of similar size and shape but differing in WL show similar trends (Betts \& Wootton, 1988): the ability to make sharp turns seems greater in slow-flying low-WL butterflies, whereas the fast flight in high-WL butterflies makes sharp turns more challenging, resulting in limited manoeuvrability.

By contrast, agility refers to the speed with which an individual can alter its flight trajectory, as estimated by the maximum roll acceleration during initiation of turns (i.e. rotational acceleration around the body axis; Norberg \& Rayner, 1987). Differential twisting, or unequal flapping of the two wings produces aerodynamic roll moment (torque). The effect of morphology on agility will depend on flight speed. Functional studies in birds and bats show that slow-flying individuals can achieve a faster turn with broad wings and rounded wing tips (Norberg, 1994; Rayner, 1988), because this wing morphology maximizes aerodynamic torque. Fast flyers have smaller and narrower wings (high $W L$ ), potentially limiting their agility. However, aerodynamic torque increases with the square of velocity such that fast flyers can achieve a high rolling moment: shorter wings are easier to beat because their mass is mostly located nearer the wing base, producing a high rolling moment that allows rapid flight path alteration even when flying at high speeds. High- $W L$ butterflies have limited manoeuvrability because of their elevated flight speed, but the higher wingbeat frequency favoured by shorter wings allows for rapid changes in direction and hence agility (Norberg, 1994). As a result, selection favouring high flight speeds may promote morphologies that constrain manoeuvring capacities (i.e. high $W L$ ). A low-WL morphology by contrast, although allowing both manoeuvrability and agility, necessarily limits flight speed.

A low $A R$ has been used as predictor of good manoeuvrability and agility in butterflies (Betts \& Wootton, 1988; Cespedes et al., 2015; DeVries et al., 2010). This association can be justified by the physical encumbrance of long wings in a cluttered environment, rather than by a functional link between $A R$ and manoeuvrability. The centre of body mass may be a more reliable predictor of manoeuvrability in butterflies: manoeuvrability measured as the percentage of successful escapes from a bird predator could be predicted accurately by the position of the centre of body mass in 27 Neotropical butterfly genera (Srygley \& Dudley, 1993). A centre of body mass close to the wing base will reduce the moment of body inertia, increasing body responsiveness and overall manoeuvrability (Ellington, 1984b).

Although the effect of $W L$ and body morphology on flight performance seems well understood, further comparative studies measuring manoeuvrability and agility in butterflies with contrasting wing morphologies could clarify the role of wing shape.

\section{(6) Fine-scale shape variation}

In spite of their aerodynamic significance, morphological predictors of flight performance such as $A R$ or moments of wing area do not accurately explain variations in wing shape within and among species. The aerodynamic consequences of subtle wing shape variations (e.g. wing outline) have been little studied.

Geometric morphometrics is a powerful tool with which to describe insect wing shape variation (e.g. Debat et al., 2003; Outomuro, Adams \& Johansson, 2013a), including butterflies (e.g. Breuker et al., 2010; Chazot et al., 2016; Klingenberg, 2010) but have rarely been used with reference to flight performance. Fine-scale variations in wing shape have been associated with predation risk in dragonflies (Outomuro \& Johansson, 2015), potentially via an effect on escape performance. Other studies have associated wing shape variations with ecological factors such as habitat use (Chazot et al., 2016), mimicry (Jones et al., 2013) and mating strategy (Johansson, Söderquist \& Bokma, 2009). Although these studies often 
struggle to provide satisfactory explanation for the observed patterns (see Section IV), they should stimulate further work on the functional consequences of fine-scale wing shape variation. Correlations between multivariate parameters characterizing wing shape with independent aerodynamic measurements may allow testing of how subtle shape variations affect flight performance [see Fraimout et al. (2018) and Ray et al. (2016) for applications to Drosophila spp.]. It will require substantial work to gather precise shape parameters and aerodynamic measurements for a sample large enough to capture within-species variation, or variation at a phylogenetic scale. Alternatively, one could use numerical simulations of flight [i.e. Computational Fluid Dynamics (CFD); see Sane, 2003] to study the aerodynamic properties of virtual wings of different shapes. For flapping flight, prior knowledge of the wingbeat kinematics is required to simulate realistic three-dimensional wing motions. Even though the use of CFD to date has been restricted to the study of individual flight performance (e.g. Liu \& Kawachi, 1998; Young et al., 2009), future work might consider it in comparative approaches (e.g. Ancel et al., 2017).

An alternative and less computationally intensive method for investigating the functional consequences of wing shape variation is the experimental manipulation of the wings of living individuals (Fernández, Driver \& Hedrick, 2017; Vance \& Roberts, 2014). This approach allows measuring the aerodynamic consequences of different types and locations of damage to the wings, thereby revealing their relative importance to flight performance (e.g. Jantzen \& Eisner, 2008). Previous work has mostly focused on the effects of gross shape variation such as symmetric versus asymmetric (Fernández et al., 2017), or spanwise versus chordwise damage (Muijres et al., 2017). Conducting similar experimental manipulations for a greater diversity of damage forms may allow a more precise identification of the wing regions that are most crucial to flight performance.

\section{(7) Three-dimensional wing shape}

The wings of butterflies are seemingly planar. Their effective shape during flight, however, is highly three-dimensional. Even at rest, butterfly wings are slightly cambered. This camber enhances lift production during flight, and is common to many effective airfoils (Vogel, 1994). During a wing stroke, the large wings of butterflies undergo dramatic deformations largely controlled by vein architecture (Combes \& Daniel, 2003a,b; Mountcastle \& Daniel, 2010; Wootton, 1981). These deformations are thought to be aerodynamically advantageous, as they may allow dynamic adaptation to the variable requirements of force production over the course of a wingbeat (Dudley, 2002). Recent work using a computational model supports this hypothesis. A model of flight aerodynamics in the Painted Lady (Vanessa cardui) obtained from a detailed kinematic analysis of wing deformation has shown greater lift force generation compared with a model assuming a non-deformable wing (Zheng, Hedrick \& Mittal, 2013). Efficiency improvements in deformable wings may stem from wing twisting or cambering causing amplification of unsteady aerodynamic mechanisms (Young et al., 2009). Well-described unsteady lift-generating mechanisms used by butterflies such as leading edge vortex (Ellington et al., 1996) or the clap and fling (Srygley \& Thomas, 2002; Weis-Fogh, 1973) have been shown to be linked to flexibility in a dynamically scaled wing model (Percin et al., 2011; Zhao, Deng \& Sane, 2011). Because wing flexibility is thus intimately linked with aerodynamic performance (at least in flapping flight), investigations of the effect of wing shape variation on flight performance should also consider the three-dimensional properties of the wings. The use of three-dimensional landmark coordinates could allow depiction of variations in wing shape during flight to be associated with measurements of flight performance. 


\section{FLIGHT MEASUREMENTS AND BEHAVIOURAL CHARACTERIZATION}

Flight performance for a given wing shape will vary depending on the flight sequence and the flight behaviour considered (e.g. take-off, escape, or courtship), with different consequences on individual fitness. The significance of morphological variation should therefore be estimated on live animals performing natural behaviours. Methods of flight measurement, however, are often of limited relevance to individual behaviour in the wild. Below we discuss the advantages and limitations of the various methods of flight quantification with reference to understanding the adaptive value of wing shape variation.

\section{(1) Methods of flight quantification: what do laboratory analyses tell us about natural behaviours?}

Flight can be quantified at different scales, ranging from the analysis of few wingbeats (e.g. Zheng et al., 2013), to a whole flight trajectory of an animal in its environment (e.g.Volponi et al., 2018) (Fig. 3). Measurements of flight performance have mostly been carried out using tethered flying insects (i.e. with the body position fixed; see Berwaerts et al., 2002; Magnan, 1934; Weis-Fogh, 1956) or on free-flying insects in a small laboratory enclosure (Srygley \& Thomas, 2002; Willmott \& Ellington, 1997a). Experimental manipulations of wing shape carried out with artificial models (Ancel et al., 2017; Park et al., 2010), and simulations using robots (Birch \& Dickinson, 2003; Muijres et al., 2017), offer a promising way of linking wing shape variations with flight performance. These approaches provide controlled conditions allowing repeated measures. Extending these results to natural flights is however questionable, given the large spectrum of behaviours displayed by butterflies in the wild. Experiments conducted in large insectary or in nature will allow us to gain insights into variation in flight patterns within and among species (Betts \& Wootton, 1988; Volponi et al., 2018), or to focus on a particular behaviour (e.g. escape flight, see Combes et al., 2012).

Associations between wing morphology and aerodynamic performance are most useful when the tested performance matches behavioural observations in nature: field experiments are thus needed to validate predictions obtained in laboratory conditions. Dudley \& Srygley (1994) measured the flight speeds of a dozen Neotropical butterfly species in both a small insectary and in the wild (when crossing a lake; see Fig. 3E). Natural flight speed was twice as high in nature relative to the insectary for the same species. Similarly, monarch butterflies have been reported to fly more slowly in the laboratory (on a tethered-flight mill) than in the wild (Davis et al., 2012). Such differences between controlled and natural conditions highlight that flight performance can be affected by laboratory settings. It should be noted that laboratory conditions may also affect insect physiology (e.g. fat and muscle mass, hydration), which could result in an altered morphology. For example, a comparison of data for the same species recorded flying in the wild and in an insectary (Dudley, 1990; Dudley \& Srygley, 1994) shows lower wing loadings in the laboratory study (Fig. 6). This difference is presumably due to a lower body weight in captive-bred individuals, which might explain their lower flight speeds. Although the speed range observed in the insectary may not reflect natural conditions, the positive covariation found in natural flights between flight speed and WL was replicated by the insectary data (Fig. 6) (Dudley \& Srygley, 1994) and thus appears robust. Flight measurements in natural or semi-natural conditions focusing on other aspects of flight performance, such as manoeuvrability, are crucially needed.

\section{(2) Flight kinematics as a measure of flight behaviour diversity}

High-speed cameras can precisely capture flight behaviours and allow the quantification of relevant flight parameters through kinematic analysis (e.g. Sridhar, Kang \& Landrum, 2016). Kinematic analysis has mostly been applied to short flight sequences recorded in laboratory settings, and has provided precise descriptions of wing and body movements in many insect 
species (Dudley, 2002; Ellington, 1984c). But kinematics can also be used to quantify the complex three-dimensional movements of butterflies in their environment, hence documenting ecologically significant behaviours [see Combes et al. (2012) for the kinematic description of aerial predation in dragonflies]. Although standardization is challenging due to variations in temperature, light intensity or air movement, kinematic analysis under natural or semi-natural conditions is of considerable interest. Characterizing whole flight trajectories is possible, allowing more realistic measurements in ecological situations. The analysis of an unperturbed flight trajectory may for example allow us to quantify natural variation in the extent of gliding versus flapping phases within and among species. Variation in kinematic parameters such as speed, acceleration or trajectory sinuosity can be analysed together, allowing a quantitative description of flight behaviour that can be related to morphological variation [see Fraimout et al. (2018) for an example on Drosophila suzukii]. The versatile flight of butterflies, however, will result in large variation even within individuals, making it more difficult to detect clear patterns. Individuals or species should be compared during similar flight modes (i.e. in gliding, flapping flight, rapid or slow forward flight, climbing or hovering), or focusing on specific aspects of flight performance. Extracting the smallest turning angle or the highest turning acceleration over the trajectory for instance, could provide a metric of manoeuvrability and agility respectively.

The most informative measurements are often those obtained when individuals are pushed to their performance limits (Dudley, 2002; Losos, Creer \& Schulte, 2002; Wainwright \& Reilly, 1994), especially where maximal performance is expressed in an ecologically relevant context. Kinematic analysis of escape behaviour may for example allow the link between speed or manoeuvrability and survival to be established (Chai \& Srygley, 1990). Manoeuvring capacity can be pushed to its limit using obstacle courses, mimicking a cluttered environment [e.g. for bumblebees (Crall et al., 2015)]. Conducting experiments in the presence of females or competing males (Bergman et al., 2007; Kemp, 2013) may allow the exploration of the effect of flight performance on reproductive success. A kinematic depiction of aerial contests performed by territorial butterflies could help to identify the aspects of flight performance involved in male-male competition (Imafuku \& Ohtani, 2006).

Recent progress in multi-camera three-dimensional videography usable in the field opens new experimental perspectives (Hedrick, 2008; Jackson et al., 2016; Theriault et al., 2014; see Dell et al., 2014 for a review). Three-dimensional tracking under natural conditions was used to describe tandem flight in swallows (Shelton, Jackson \& Hedrick, 2014), courtship behaviour in hummingbirds (Clark, 2009), and inter-tree gliding in flying squirrels (Bahlman et al., 2013). Similar three-dimensional quantification of natural flight behaviours could be applied to butterflies to investigate links between morphology and performance in an ecologically relevant context. More generally, acquisition of kinematic data in a greater variety of taxa is needed to characterize the functional consequences and behavioural implications of the morphological diversity of butterflies. 


\section{WHAT SELECTIVE FACTORS INFLUENCE FLIGHT AND ASSOCIATED WING MORPHOLOGY?}

Both selective and neutral factors are likely involved in the evolution of the wide diversity of wing size and shape exhibited across butterfly species. Morphological evolution may be influenced by both biomechanical constraints and trade-offs between different selective pressures. Investigating how flight performance associated with wing variations affects the resource acquisition, survival, or reproductive success of individuals could shed light on the evolutionary forces involved in wing diversification. Within species, linking variation in morphology with differences in fitness-related behaviours could demonstrate the influence of selection. In most cases however, morphological variation within species is low, and contrasting morphologies are mostly observed among species with different ecologies. Such ecomorphological patterns observed at the macro-evolutionary scale may result either from selection or from neutral divergence during their phylogenetic history. As discussed below, support for adaptive evolution is often obtained through correlations between wing shape and ecological factors, although identifying the precise causal factors underlying such correlations is often a major challenge. Here we review the evidence for natural and sexual selection driving wing shape evolution in butterflies. We specifically evaluate whether a significant departure from neutral evolution has been detected and whether specific adaptive mechanisms have been identified.

\section{(1) Microhabitat}

Habitat is often mentioned as a factor influencing the evolution of wing morphology (Cespedes et al., 2015; Chazot et al., 2016; Outomuro, Dijkstra \& Johansson, 2013b). Ecological niches differ among habitats (e.g. predators, vegetation density, resources availability, etc.), likely generating contrasting selection on flight abilities. Some striking differences in habitat can be associated with wing shape variation in butterflies. Species inhabiting Neotropical forests are often segregated vertically (Devries \& Walla, 2001) and wing shape tends to differ among those microhabitats. For example, in the butterfly genus Morpho, differences in wing morphology are found between species that fly mostly at the canopy level, and those typically seen in the understorey. Measurements of moment of wing area and $A R$ (DeVries et al., 2010) as well as landmark-based geometric morphometric analyses (Chazot et al., 2016) revealed that canopy species exhibit a wing morphology that enhances gliding capacity, while the wings of understorey species may be more efficient in manoeuvres and flapping flight. Wing shape differences between the two microhabitats were stronger than expected under neutral phylogenetic divergence, suggesting adaptive divergence in these microhabitats. A cluttered environment such as the understorey may indeed favour morphological and behavioural adaptations that improve manoeuvrability, in contrast to the open canopy which allows extensive periods of gliding flight. The precise nature of the selective pressure(s) involved however remains hypothetical. A morphometric comparison was conducted across satyrine taxa known from field observations either to glide close to the ground or to use flapping flight above the forest floor (Cespedes et al., 2015). Gliding behaviour is advantageous close to the ground because of up-wash generated via a mirroring effect (i.e. the 'ground effect'; Rayner, 1991). Convergence of wing shape towards typical glider morphology was observed among distantly related satyrine taxa displaying gliding behaviour, as well as morphological divergence from closely related species with different flight behaviours. No biomechanical study however has yet described the 'ground effect' in gliding insects. Further focus on satyrine gliding behaviour should help us to understand the mechanisms underlying this observed association between wing morphology and flight.

The spatial complexity of a habitat and its variation among forest strata undoubtedly constrain flight behaviour in butterflies. A less-often considered factor is the wind 
environment. While the forest floor is relatively free of wind, there is a gradual increase in wind velocity and variability nearer to the canopy (Allee, 1926; Kruijt et al., 2000). Butterflies flying at the canopy level or in open areas, while less affected by environmental cluttering, are exposed to air movement instabilities. Combes \& Dudley (2009) showed experimentally that turbulence variations impact flight performance in orchid bees, particularly affecting maximum flight speed and stability. Interestingly, active stabilization via hindleg extension was observed in response to increased flow speed and variability. Similarly, the kinematic responses of hawkmoths flying through artificially generated turbulent flow led to a reduced flight speed (Ortega-Jimenez et al., 2013). Butterflies inhabiting more open environments with their inherent airflow instability may therefore display morphobehavioural adaptations to wind. Vertical stratification in the rainforest appears to be an important factor driving the evolution of wing shape in butterflies although further investigations are needed. Quantifying flight behaviour among species living in different forest strata, or assessing flight manoeuvrability in experimentally cluttered (e.g. Crall et al., 2015) or windy (e.g. Combes \& Dudley, 2009) environments, for example, could clarify the role of spatial configuration on flight behaviour.

Other ecological factors that differ among habitats may also influence flight behaviour and wing shape evolution. Variation in daily activity period will result in differences in exposure to sunlight, which is important in butterflies for warming up flight muscles. Diurnal species are less constrained in their time of activity (Freitas et al., 1997), and may thus spend more time flying than crepuscular species, and exhibit wing shapes associated with reducing the energy requirements of flight. Penz \& Heine (2016) investigated whether diurnal or crepuscular behaviour was reflected in wing morphology across species of Brassolini. Accounting for phylogenetic divergence, they found that wings of diurnal species had a significantly higher $A R$ and lower wing moment of area than wings of crepuscular species, implying that the temporal niche indeed may affect butterfly wing morphology. Whether diurnal species do spend more time in flight relative to crepuscular species remains to be shown, and the influence of other ecological factors influencing flight duration (e.g. matelocating strategy, see Section IV.5 and 6) should also be investigated to identify the nature of selection.

Differences in spatial or temporal niche may also be associated with variation in food resources. Hall \& Willmott (2000) found a link between feeding preferences and wing morphology among Neotropical Riodinidae. Species preferring sodium-rich substrates (like rotting fish or moist surfaces) had a significantly higher WL. A similar effect was observed among European nectar-feeding butterflies, where species with high $W L$ forage mainly on aggregated or unusually nectar-rich flowers, while low-WL species were more likely to include solitary or less nectar-rich flowers in their diet (Corbet, 2000). It is unclear whether the higher WL observed in species relying on nutrient-rich resources reflects increased selection on flight performance in species with intensive foraging activities or conversely selection on resource acquisition in species with a high WL. A high WL indeed characterizes fast and powerful flyers with high metabolic rates, for which a high energy intake will be necessary to maintain high levels of neuromuscular activity (Arms, Feeny \& Lederhouse, 1974). Specific constraints may be imposed on flight behaviour by feeding habits. For example, the exceptional hovering abilities found in sphingid moths have probably coevolved with their nectar-feeding habits, resulting in their adapted wing morphology (i.e. high $A R$ and $W L)$.

Identifying the selective forces affecting wing shape in relation to habitat ultimately requires a detailed description of feeding resources, habitat configuration, spatial distribution of host plants, and assessment of variations in fitness-related traits in these different environments. 


\section{(2) Predation}

Wing morphology not only directly determines escape abilities but the wings also represent the main visual cue attracting the attention of predators: butterfly wings are particularly large and conspicuous relative to most insects. Their flight trajectory is typically erratic and unpredictable, potentially making them harder to catch. Interestingly, Jantzen \& Eisner (2008) showed experimentally that butterfly hindwings play an important role in their typical zig-zag, evasive flight. Such erratic flight conferred by hindwings likely plays a role in escaping from predators; it might even contribute discouraging predators by advertising their evasiveness (Humphries \& Driver, 1970). Particularly visible aspects of the wings can also contribute deceiving predators. Many butterflies display more or less extended tails on the hindwings. These tails have been shown to deflect attacks away from vital body parts (Barber et al., 2015), for example, some lycaenid species have tails that closely resemble the butterfly's head (e.g. among the Eumaeini tribe). Robbins (1981) showed that this resemblance led to more frequent wing damage caused by deflected predator attacks. These lycaenid species perform a typical behaviour consisting of alternate back and forth movements of the hindwings - and thus of the head-like tails - possibly reinforcing the deceptive effect (López-Palafox, LuisMartínez \& Cordero, 2015; Robbins, 1980). However another experimental test using mantids as predators did not detect any survival advantage associated with the presence of tails (López-Palafox \& Cordero, 2017), suggesting that the proposed deflection role of the lycaenid tail may be dependent on the predator involved. Hindwing tails can be very elongated in some butterflies (e.g. Papilionidae) and moths. An anti-predation effect against bats has been demonstrated in the nocturnal moth Actias luna: wing tails deflect attacks away from essential body parts, increasing survival relative to individuals whose tails were experimentally removed (Barber et al., 2015). Longer hindwing tails have been shown to increase their deflecting effect (Rubin et al., 2018). It should be noted however, that tailless individuals also displayed a higher wingbeat frequency, potentially required to compensate for reduced lift or weaker gliding capacity, implying that damage to the wing tails does carry a cost. As discussed above, hindwings tails improve gliding performance (Park et al., 2010), so this morphology might have evolved in response to several selective pressures.

Predator communities may vary across habitats, leading to different selection pressures on wing shape and flying abilities. Quantifying variations in predator community and putative predation risk in different environments is a challenging task, and data on butterflies' predators are scarce. A recent study (Willmott et al., 2017) showed that encounter rates between insectivorous birds and butterflies (mostly from the Ithomiini tribe) differed significantly between forest strata. Butterflies living in the understorey may be more prone to attacks from reptiles or mantids, which may select for specific flight abilities (e.g. rapid take off). Investigating escape abilities in butterfly species occupying different forest strata may shed light on the effects of variation in predator types. Interestingly, heavy predation may not necessarily select for enhanced escape ability as other morphological and behavioural adaptations such as immobility in cryptic species may be more effective.

Some butterfly species have evolved chemical defences associated with warning colour patterns (i.e. aposematism). By quantifying flight pattern among 53 Neotropical species, Chai \& Srygley (1990) showed that palatable butterflies are generally fast and erratic flyers, while unpalatable ones display slower and more predictable flight. Experimental trials with birds showed that palatable species had a greater escape success (Chai \& Srygley, 1990; Pinheiro, 1996). Morphological comparisons suggested contrasting energy investments between palatable and unpalatable butterflies, either into thorax muscles or abdominal mass, respectively (Srygley, 1994, 2004; Srygley \& Dudley, 1993). Such divergence in flight behaviour and body morphology among palatable and unpalatable butterflies has likely been 
accompanied by changes in wing morphology. Many unpalatable species typically show both a high $A R$ and high second moment of area (i.e. elongated wings with most of the wing area located distally) such as in the Heliconiini or Ithomiini tribes for example (upper right in Fig. 4). Their elongated wing shape and low WL (upper left in Fig. 5) results in slow flight and a lower energy cost of flight relative to palatable species (Srygley, 2004). This energy may be re-allocated into chemical protection achieved via sequestering toxic substances from their host plants or neo-synthesis (Nishida, 2002), or into larger guts and ovaries (Marden \& Chai, 1991) allowing greater fecundity. The evolution of unpalatability in butterflies might thus have triggered a shift in energy allocation from flight muscles towards the synthesis of toxins and reproductive tissues.

Wing toughness, resulting from thickness and venation, has been shown to be greater in unpalatable relative to palatable butterflies in several African species (DeVries, 2002, 2003). Protected species are then more likely to survive after being released by predators deterred by noxious substances. The greater fragility of wings in palatable species is suggested to favour wing breaking, which may allow them to escape when grasped by a predator (Srygley, 1994) and is probably due to the presence of fewer wing venation elements near the wing tips. In addition, palatable species have an extended area at the base of the hindwing covering their abdomen. This wing position, as opposed to the long exposed abdomen of unpalatable species, may reduce the risk of injury during an attack by a predator (Chai \& Srygley, 1990), although it may simultaneously provide an aerodynamic advantage by creating a continuous aerofoil, theoretically reducing drag during gliding (Ellington, 1984b), or enhance conservation of heat (Kingslover \& Koehl, 1985; Wasserthal, 1975). Morphologies favouring the maintenance of a high body temperature might be promoted in palatable species, with their higher energy requirements for flight. Srygley \& Chai (1990) showed that palatability is positively associated with body temperature across distantly related lineages. Palatable butterflies may thus be constrained to warmer microhabitats with easier access to sunlight, or to restrict activity to the hottest hours of the day. This trend was noticed by Wallace (1865), who described fast-flying species as 'sun-lovers', and slower ones as being active in the shade. The striking behavioural and morphological evolutionary divergences observed between palatable and unpalatable butterflies thus illustrate the evolution of contrasting wing morphologies in response to predation pressure.

\section{(3) Morpho-behavioural convergence: when mimicry goes beyond colour pattern}

Convergence of wing colour pattern between unpalatable butterflies, i.e. Müllerian mimicry, is promoted because sharing a common signal of unpalatability allows sharing the cost of predator education, and therefore reduces individual risk of predation (Müller, 1879; Sherratt \& Beaty, 2003). Distantly related butterfly species living in sympatry therefore frequently converge toward a single warning signal, forming so-called mimicry rings. Palatable species can also display mimetic wing colour patterns, therefore benefiting from the protection associated with locally known warning signal without paying the cost of carrying the chemical defence (i.e. Batesian mimicry; Bates, 1862). Batesian mimics however do not contribute to predator education and therefore increase the predation risk for the mimicked models. In addition to the well-documented visual resemblance among butterfly species within mimicry rings, there is also convergence in flight pattern. In Müllerian mimic pairs of the genus Heliconius, kinematic parameters (such as wingbeat frequency and wing elevation relative to the body) were found to be more similar among distantly related co-mimics than among non-mimetic sister species (Srygley, 1999). In Papilio polytes, females are polymorphic, with one morph resembling an unpalatable sympatric toxic butterfly (Pachliopta aristolochiae), while the other morph resembles its conspecific non-mimetic male (i.e. female-limited Batesian mimicry). The two female morphs were shown to have significantly 
different flight trajectories, with the female Batesian mimic flying more similarly to its unpalatable model than to its non-mimetic conspecific morph (Kitamura \& Imafuku, 2015). More recently, the flight trajectory of bee-mimicking and wasp-mimicking moths (Sesiidae) was shown to differ, with a flight behaviour closer to their respective model species than to more closely related species (Volponi et al., 2018). Such 'locomotor mimicry' is thought to enhance the protection associated with mimetic warning coloration (Srygley, 1994).

Convergence in flight behaviour among mimetic species will likely affect wing morphology. Morphological comparisons between mimetic pairs in the genus Heliconius indeed showed that the position of the centre of body mass as well as wing shape were more similar within than among mimetic pairs (Jones et al., 2013; Srygley, 1994; Srygley \& Ellington, 1999), suggesting coevolution between wing shape, colour pattern and possibly flight behaviour. Batesian mimics, however, do not deter predators and are thus not released following capture, generating a trade-off between mimetic flying abilities and escape capacity (Srygley, 1994; Srygley \& Chai, 1990). Srygley (2004) estimated the aerodynamic cost of flight of three Batesian mimics and their unpalatable models, and two non-mimetic sister species: flight cost was higher in Batesian mimics relative to their model, but also higher than their non-mimetic sister species. Analysis of wingbeat kinematics revealed slower wing motion in the cheater relative to its non-mimetic sister species. Unpalatable models can thus invest more in abdominal mass and have greater energy reserves than palatable Batesian mimics that invest more in flight muscles. Benefiting from accurate flight similarity to its model while having a 'maladapted' morphology may thus be achieved at a higher energy cost. Further studies on a larger range of species could confirm the generality of this result and clarify which features are responsible for the added cost of flight in the cheater.

\section{(4) Long-distance flight in response to fluctuating environments}

Many flying animals migrate over long distances in response to temporal or spatial changes in environment (Dingle, 2009). The ability to migrate is often linked to higher survival and reproductive success (Holland, Wikelski \& Wilcove, 2006), potentially inducing strong selection for wing morphology that reduces flight energetic costs. Although no macroevolutionary studies focusing on the effect of migration on wing morphology have been conducted in butterflies, evidence for adaptation of wing shape to long-distance flight has been found at the intraspecific level. Several studies have compared migratory and nonmigratory populations of the monarch butterfly (Danaus plexippus) (Altizer \& Davis, 2010; Arango Velez, 1996; Dockx, 2007). Monarchs flying thousands of kilometres across North America from breeding to overwintering sites have a significantly larger $A R$ and a lessvariable forewing length than those from populations remaining year-round in Caribbean islands. Migrant monarchs use gliding flight extensively during migration (Gibo \& Pallett, 1979), therefore benefiting from wings with a large $A R$. Consistent with this finding, in the agricultural pest diamondback moth (Plutella xylostella), transocean migrants have a very high AR (Chen et al., 2015; Chu, 1986), as does the diurnal moth Urania fulgens which performs massive migrations from Mexico to Ecuador (Williams, 1930). Behavioural adaptations have also been highlighted in migrating species: the long-winged moth Autographa gamma that migrates between the UK and North Africa (Hill \& Gatehouse, 1993) has been shown actively to select the fastest airstreams, thereby maximizing migration speed and distance (Chapman et al., 2008). Such associations between migratory behaviour and wing morphology documented in few species indicate that it would be productive to investigate the link between migratory behaviour and wing morphology across a larger number of species. Interestingly, a large $A R$ is not found in all migrating butterflies: sulfur butterflies (Phoebis sennae) for example, migrate over the Caribbean Sea but have rather compact wings (Brown \& Heineman, 1972). Selection for migratory ability associated with 
the evolution of elongated wings may thus conflict with selective pressures acting on other flight abilities (e.g. manoeuvrability in cluttered environments) and trade-offs between these may explain the variations in $A R$ known among migrating butterfly species.

In the diamondback moth, wing length is negatively correlated with fecundity, and positively correlated with flight duration capacity (Muhamad et al., 1994), suggesting a fecundity-migration trade-off [see Roff \& Fairbairn (2007) for a general discussion in insects]. Pellegroms et al. (2009) showed that Pararge aegeria females raised under poor nutritive conditions had more elongated wings. The production of a morphology associated with a reduced cost of flight when resources are limited could be interpreted as adaptive plasticity.

\section{(5) Sex-specific behaviours}

Male and female butterflies have different life-histories (Wiklund, 2003) and may thus differ in flight behaviours. Striking divergence in flight behaviour and/or microhabitat between the sexes is implied by the scarcer observations of females in the field and their underrepresentation in collections. The available data suggest higher flight activity in males relative to females: flight duration from field observations was higher in male Heodes virgaureae (Douwes, 1976), Euphydryas phaeton (Gilchrist, 1990) and in males from four Colias species (Kingsolver, 1983). Lower flight activity in females might be due to their more cryptic behaviour, i.e. preferring denser vegetation, searching for potential host plants. Males, by contrast, spend long periods patrolling to search for mates, and are thus more likely to be seen (DeVries, 1987; Shreeve, 1987; Wickman, 1992). Interestingly, experimental estimations of flight endurance do not reflect this. For example, some studies of Pieris brassicae reported higher flight endurance in females relative to males (Ducatez et al., 2013; Reim et al., 2018). Thus, the generally lower flight activity observed in females may not reflect weaker flight capacity, but could simply reflect behavioural adjustments to save energy. Females are generally heavier (due to greater abdominal mass and eggs), but are also larger, probably because of natural selection promoting increased fecundity (Gilchrist, 1990). A higher weight will result in higher flight costs, potentially translating into shorter periods of slower flight. Males by contrast, have a greater thoracic mass, resulting in more flight muscles per unit body mass and allowing them greater flight power and acceleration (Karlsson \& Wickman, 1990). The relatively small size of males has been suggested to result from sexual selection favouring rapid development leading to early emergence and increased mating opportunities (Gilchrist, 1990; Wiklund \& Fagerström, 1977). Alternatively smaller size might mitigate the higher predation risk associated with their extensive flight activity (Allen, Zwaan \& Brakefield, 2011). Studies estimating predation risk from beak marks in natural populations (Ide, 2006; Ohsaki, 1995) suggest that females are attacked significantly more often, a result consistent with the better escape ability conferred by male morphology.

Differences in body morphology and flight behaviour between the sexes are likely to influence the evolution of wing morphology, resulting in wing sexual dimorphism. Females tend to have a larger wing area relative to males, probably compensating for their greater body weight, although their WL generally remains higher than that of males (Gilchrist, 1990). In species where males spend significantly more time flying relative to females, a wing morphology optimizing flight cost, such as a larger $A R$, may be favoured. A larger $A R$ in males is known in Pararge aegeria (Berwaerts et al., 2002), in the potato pest moth Tecia solanivora (Hernández-L et al., 2010), and in several Neotropical butterfly species (Cespedes et al., 2015; DeVries et al., 2010; Mendoza-Cuenca \& Macías-Ordóñez, 2005). In monarch butterflies, a higher $A R$ was found in migrant females relative to residents, while no such difference was detected among males, possibly because both migrating and resident males are adapted to long flight periods due to their patrolling behaviour (Dockx, 2007). As discussed 
above, $A R$ does not encompass all aspects of wing shape, so that males and females may exhibit different wing shapes but still have a similar $A R$. For example, a study of Heliconius numata detected significant wing shape dimorphism using geometric morphometrics, with no difference in $A R$ (Jones et al., 2013). Males exhibited a broader wing base due the presence of the androconial patch (a pheromone-disseminating organ near the forewing base), decreasing the moment of wing area. Geometric morphometrics also highlighted wing shape dimorphism in the genus Morpho, and variation in its extent among species (Chazot et al., 2016). Although sexual dimorphism could result from natural selection acting differently on male and female wing morphology due to contrasting flight behaviours, sexual selection may also be involved.

\section{(6) Sexual selection}

Female mate choice based on male wing coloration has been documented in several butterfly species (Costanzo \& Monteiro, 2007; Kemp, 2007, 2013; Robertson \& Monteiro, 2005), but inter-sexual selection on wing shape is relatively understudied. One study using paper models to investigate mating behaviour in Graphium sarpedon failed to detect any effect of variation in wing shape on the frequency of male approaches (Kato \& Yoshioka, 2003), but whether females adjust their choice according to male wing shape has not been tested. The role of wing morphology in inter-sexual selection may also be considered in the context of aerial courtship. In birds, there is morphological divergence between species in which male birds perform song flights and those who do not (Hedenström \& Møller, 1992). Elaborate aerial interactions are commonly observed in butterflies [e.g. Argynnis paphia (Magnus, 1950); Hipparchia semele (Tinbergen, Meeuse \& Varossieau, 1942)]. Although these also occur between males in the form of contest or 'erroneous courtship' (Takeuchi, 2017), aerial interactions between males and females are thought to place the male scent organ close to the female antennae (Scott, 1973). Successful mating is likely favoured by high manoeuvring and hovering abilities and associated wing morphology. These aspects of flight performance will also be advantageous in other situations (e.g. escape from predators, flight in cluttered habitats, etc.), and therefore likely to be subject to both natural and sexual selection. Comparative studies investigating wing morphology among butterfly species with different courtship behaviours would be informative.

In contrast to inter-sexual selection, the effect of intra-sexual selection on the evolution of butterfly wing morphology is well documented (Berwaerts et al., 2006; Estrada et al., 2010; Scott, 1974; Shreeve, 1984, 1987; Wickman, 1992). Male-male competition occurs in many butterfly species, and can result in different mate-locating behaviours. In some Heliconius species, males monitor female pupae until emergence, thereby increasing their chances of mating with virgin females (i.e. 'pupal-mating', see Estrada et al., 2010). Interestingly, in $H$. charitonia, some males have been reported to adopt an alternative strategy known as patrolling: they fly continuously in search for females (Mendoza-Cuenta, 2004). The different mate-locating strategies are associated with morphological differences: pupal-mating males are larger than patrollers, which is thought to confer an advantage during scramble competition (i.e. when several males simultaneously occupy a female pupa) (Deinert, 2003). The smaller patrolling males have a larger $A R$ relative to their conspecific pupal-maters, likely reducing the cost of sustained flight on which they rely to find mates (Mendoza-Cuenca \& \& Macías-Ordóñez, 2005). Patrolling behaviour is widespread in many butterfly taxa, along with another strategy known as perching (Rutowski, 1991; Scott, 1974; Wickman, 1992). Perching males typically sit and wait in sunlit vegetation patches, and take off rapidly to intercept conspecific males and females with a circling flight (Shreeve, 1987; Wickman, 1992). Because for each strategy the flight performance improving mating success will be different (i.e. low cost sustained flight versus rapid acceleration), selection may have favoured 
contrasting morphology (wing shape, flight muscles and thorax size) in perchers versus patrollers. Investigating 42 butterfly species with known phylogenetic relationships and matelocating behaviour, Wickman (1992) showed that percher species have a relatively larger thorax compared to patrollers, in agreement with selection on flight morphology promoting rapid take-off and high acceleration. Interestingly, variation in mate-locating behaviour also occurs within butterfly species (Shreeve, 1992). In Pararge aegeria, field observations (Van Dyck, Matthysen \& Dhondt, 1997) suggest marked intraspecific behavioural divergence. Morphological comparisons showed that perchers have heavier thoraxes than patrollers, mirroring the pattern previously observed at the macro-evolutionary scale. Finally, Berwaerts et al. (2008) showed that acceleration during take-off has a significant heritable component in male but not in female $P$. aegeria. Clearly, different flight behaviours can lead to divergent morphological evolution both within and among species.

The link between body morphology and mate-searching behaviour is well established, however its co-evolution with wing morphology is still poorly understood. Elongated wings are expected in patrollers because they are predicted to reduce flight cost. Nevertheless, perchers tend to exhibit a higher wing length and $A R$ than patrollers (Van Dyck et al., 1997; Wickman, 1992). In Pararge aegeria, a higher $A R$ was correlated with higher acceleration capacity, body mass, thorax mass, forewing area, forewing length, and centre of forewing area (Berwaerts et al., 2002, 2006), preventing a straightforward identification of the functional links. Such discrepancies between aerodynamic expectations and realized behaviours questions the use of $A R$ as a predictor of flight performance, and emphasize the need to quantify wing shape variations and their interactions with body morphology.

\section{CONCLUSIONS}

(1) We documented interactions between wing morphology, behaviour and ecology in butterflies and reviewed current knowledge on the selective forces driving wing shape diversity.

(2) At the macro-evolutionary level, comparative analyses have identified deviations from neutral expectations, suggesting correlations between wing shape variables and ecological factors. However, most correlations with ecological factors (such as flight height or time of activity) do not allow us to identify the underlying selective forces. The macro-evolutionary trends detected should motivate field studies characterizing flight behaviour, predator community, mating strategy and feeding habits among butterfly taxa. Ecological and behavioural studies are needed to estimate the effect of wing shape variations on fitnessrelated traits in different environments. Experimental tests of putative selective mechanisms acting on the evolution of flight and associated wing shape within species might provide useful insights on wing shape evolution at a larger scale, although variations in both behaviour and morphology are generally smaller within species.

(3) Habitat, predation and sex-specific behaviours are likely to be major selective forces acting on wing shape evolution. The most convincing cases of morphological divergence reported in the literature are usually related to the evolution of body morphology, and more particularly to the relative investment in flight muscles, rather than to wing shape. Two hypotheses could account for this trend. (1) Body morphology might respond faster to selection acting on flight than wing shape. As previously highlighted, both wing shape and thorax morphology will result from a complex trade-off between several selective pressures but flight muscle s can be flexibly used while wing shape is fixed. Wing shape evolution might thus be more subject to deleterious pleiotropic effects than thorax morphology, whose modifications might be buffered by behaviour. For example, genetic manipulation of wing shape in Drosophila melanogaster was found to improve flight agility but increased the cost of flight (Ray et al., 2016). This higher flight cost was suggested to result from a disjunction 
between wing shape and muscle morphology: wing shape alteration that is not accompanied by changes in the musculoskeletal apparatus may be detrimental. Clearly, wing shape and body morphology should be considered together as an integrated phenotype. Alternatively, (2) a significant association between wing shape and flight performance may be reported less frequently because of methodological challenges involved in wing shape quantification. Simple parameters such as $A R$ can be misleading, preventing us from fully understanding morpho-functional links. The advent of powerful morphometric methods allowing the detailed quantification of wing shape (e.g. Bookstein, 1997; Klingenberg, 2010; Rohlf \& Marcus, 1993) and the wide availability of morphometrics tools (e.g. Adams \& Otárola- Castillo, 2013; Claude, 2008; Klingenberg, 2011; Rohlf, 2015) might facilitate the identification of wing shape variations relevant to flight performance. Ongoing methodological advances also allow the analysis of insect flight through kinematic and aerodynamic force measurements with increased precision (Ancel et al., 2017; Hedrick, 2008; Sridhar et al., 2016). Combining these approaches with the precise quantification of wing shapes should help us to understand the effects of wing shape variations on aerodynamic performance.

(4) Investigating flight behaviour in natural conditions is required to identify the adaptive roles of morphological variations. Field studies characterizing butterfly flight behaviour in detail will allow a better understanding of the adaptive processes shaping butterfly wing diversity.

(5) Finally, our review highlights the interest of combining results from ecology and aerodynamics. A better understanding of the evolutionary mechanisms driving wing shape diversity requires precise knowledge of the functional consequences of morphological variation. While new insights on the functional morphology of insect flight have arisen from engineering studies on bio-inspired flight systems (Liu et al., 2016), these still remain distant from ecological research approaches. We advocate a higher level of interaction between these research fields.

\section{ACKNOWLEDGEMENTS}

The authors would like to thank Ramiro Godoy-Diana, Raphaël Cornette, Robert Srygley, Melanie McClure and Florian Muijres for stimulating discussions on the evolution of flight and wing shape in butterflies. We are grateful to Mirko Kovak, Kristjan Niitepõld, Robert Srygley, Adrian Thomas, Marcos Guerra and Robert Dudley for providing photographs. We thank Marianne Espeland for providing a phylogeny of butterflies. We are grateful to two anonymous reviewers for their constructive comments on a previous version. This research was funded by the Université Paris Descartes, the Ecole Doctorale Frontières du Vivant (FdV) - Programme Bettencourt, and the LabEx BCDiv to C.L.R. and the Emergence program of Paris city council to V.L.

\section{REFERENCES}

ADAMS, D. C. \& OTÁROLA- CASTILLO, E. (2013). geomorph: an R package for the collection and analysis of geometric morphometric shape data. Methods in Ecology and Evolution 4, 393-399.

Ahmad, A. (1984). Comparative study on flight surface and aerodynamic parameters of insects, birds and bats. Indian Journal of Experimental Biology 22, 270-278.

ALDRIDGE, H. (1987). Turning flight of bats. Journal of Experimental Biology 128, 419-425.

ALLEE, W. C. (1926). Measurement of environmental factors in the tropical rain-forest of Panama. Ecology 7, 273-302.

Allen C. E., ZWAan, B. J. \& Brakefield, P. M. (2011). Evolution of sexual dimorphism in the Lepidoptera. Annual review of entomology 56, 445-464.

Altizer, S. \& DAVIS, A. K. (2010). Populations of monarch butterflies with different 
migratory behaviors show divergence in wing morphology. Evolution 64, 1018-1028.

Ancel, A. O., Eastwood, R., Vogt, D., Ithier, C., Smith, M., Wood, R. \& Kovač, M. (2017). Aerodynamic evaluation of wing shape and wing orientation in four butterfly species using numerical simulations and a low-speed wind tunnel, and its implications for the design of flying micro-robots. Interface Focus 7, 20160087.

ARANGO VELEZ, N. (1996). Stabilizing selection in migratory butterflies: a comparative study of queen and monarch butterflies. Unpublished Masters thesis, University of Florida, Gainesville, Florida.

Arms, K., FeEny, P. \& Lederhouse, R. C. (1974). Sodium: stimulus for puddling behavior by tiger swallowtail butterflies, Papilio glaucus. Science 185, 372-374.

ARnold, S. J. (1983). Morphology, performance and fitness. American Zoologist 23, 347361.

Bahlman, J. W., Swartz, S. M., Riskin, D. K. \& Breuer, K. S. (2013). Glide performance and aerodynamics of non-equilibrium glides in northern flying squirrels (Glaucomys sabrinus). Journal of The Royal Society Interface 10, 20120794.

BAlmford, A., ThOmAs, A. L. \& Jones, I. L. (1993). Aerodynamics and the evolution of long tails in birds. Nature 361, 628-631.

Barber, J. R., Leavell, B. C., Keener, A. L., Breinholt, J. W., Chadwell, B. A., McClure, C. J., Hill, G. M. \& Kawahara, A. Y. (2015). Moth tails divert bat attack: Evolution of acoustic deflection. Proceedings of the National Academy of Sciences 112, 2812-2816.

Bartholomew, G. A. \& CASEy, T. M. (1978). Oxygen consumption of moths during rest, pre-flight warm-up, and flight in relation to body size and wing morphology. Journal of Experimental Biology 76, 11-25.

Bates, H. W. (1862). XXXII. Contributions to an insect fauna of the Amazon Valley. Lepidoptera: Heliconidæ. Transactions of the Linnean Society of London 23, 495-566.

Bergman, M., Gotthard, K., Berger, D., Olofsson, M., Kemp, D. J. \& WiKlund, C. (2007). Mating success of resident versus non-resident males in a territorial butterfly. Proceedings of the Royal Society of London B: Biological Sciences 274, 1659-1665.

Berwaerts, K., AERTS, P. \& VAN DYCK, H. (2006). On the sex-specific mechanisms of butterfly flight: flight performance relative to flight morphology, wing kinematics, and sex in Pararge aegeria. Biological Journal of the Linnean Society 89, 675-687.

Berwaerts, K., MATTHYSEn, E. \& VAN DyCK, H. (2008). Take-off flight performance in the butterfly pararge aegeria relative to sex and morphology, a quantitative genetic assessement. Evolution 62, 2525-2533.

BERWAERTS, K., VAN DYCK, H. \& AERTS, P. (2002). Does flight morphology relate to flight performance? An experimental test with the butterfly Pararge aegeria. Functional ecology 16, 484-491.

Betts, C. \& Wootton, R. (1988). Wing shape and flight behaviour in butterflies (Lepidoptera: Papilionoidea and Hesperioidea): a preliminary analysis. Journal of Experimental Biology 138, 271-288.

BIRCH, J. M. \& DiCKINSON, M. H. (2003). The influence of wing-wake interactions on the production of aerodynamic forces in flapping flight. Journal of Experimental Biology 206, 2257-2272.

BONINE, K. E. \& GARLAND JR, T. (1999). Sprint performance of phrynosomatid lizards, measured on a high-speed treadmill, correlates with hindlimb length. Journal of Zoology 248, 255-265.

Bookstein, F. L. (1997). Morphometric tools for landmark data: geometry and biology. Cambridge University Press.

Braby, M. F., Vila, R. \& Pierce, N. E. (2006). Molecular phylogeny and systematics of the 
Pieridae (Lepidoptera: Papilionoidea): higher classification and biogeography. Zoological Journal of the Linnean Society 147, 239-275.

Braun, A. F. (1924). The frenulum and its retinaculum in the Lepidoptera. Annals of the Entomological Society of America 17, 234-257.

Breuker, C. J., GibBs, M., Van Dongen, S., MerckX, T. \& VAn Dyck, H. (2010). The use of geometric morphometrics in studying butterfly wings in an evolutionary ecological context. In Morphometrics for Nonmorphometricians, pp. 271-287. Springer.

BRodsKy, A. K. (1994). The evolution of insect flight. Oxford University Press.

Brown, F. M. \& Heineman, B. (1972). Jamaica and its Butterflies. E. W. Classey Ltd, London.

Byrne, D. N., Buchmann, S. L. \& Spangler, H. G. (1988). Relationship between wing loading, wingbeat frequency and body mass in homopterous insects. Journal of Experimental Biology 135, 9-23.

Cespedes, A., Penz, C. M. \& DeVries, P. J. (2015). Cruising the rain forest floor: butterfly wing shape evolution and gliding in ground effect. Journal of Animal Ecology 84, 808-816.

Chai, P. \& SRYgley, R. B. (1990). Predation and the flight, morphology, and temperature of neotropical rain-forest butterflies. American Naturalist 135, 748 -765.

Chapman, J. W., Reynolds, D. R., Mouritsen, H., Hill, J. K., Riley, J. R., Sivell, D., SMITH, A. D. \& WoIWOD, I. P. (2008). Wind selection and drift compensation optimize migratory pathways in a high-flying moth. Current Biology 18, 514-518.

Chazot, N., Panara, S., Zilbermann, N., Blandin, P., Le Poul, Y., Cornette, R., Elias, M. \& DEBAT, V. (2016). Morpho morphometrics: Shared ancestry and selection drive the evolution of wing size and shape in Morpho butterflies. Evolution 70, 181-194.

Chen, J., WANG, Z., ZhANG, J., ZHANG, L. \& WU, G. (2015). Numerical simulation for changes in aerodynamic characteristics along the spanwise of "diamond back" wing. Procedia Engineering 99, 566-574.

Chin, D. D. \& LentinK, D. (2016). Flapping wing aerodynamics: from insects to vertebrates. Journal of Experimental Biology 219, 920-932.

CHU, Y.-I. (1986). The migration of diamondback moth. In Diamondback moth management (eds N. S. TALEKAR and T. D. GrigGS), pp. 77-81. Asian Vegetable Ressources and Development Center, Shanhua, Taiwan.

Clark, C. J. (2009). Courtship dives of Anna's hummingbird offer insights into flight performance limits. Proceedings of the Royal Society of London B: Biological Sciences, rspb20090508.

Claude, J. (2008). Morphometrics with R. Springer Science \& Business Media.

Combes, S. \& DANiel, T. (2003a). Flexural stiffness in insect wings I. Scaling and the influence of wing venation. Journal of Experimental Biology 206, 2979-2987.

Combes, S. \& DANIEL, T. (2003b). Flexural stiffness in insect wings II. Spatial distribution and dynamic wing bending. Journal of Experimental Biology 206, 2989-2997.

Combes, S. A. \& Dudley, R. (2009). Turbulence-driven instabilities limit insect flight performance. Proceedings of the National Academy of Sciences 106, 9105-9108.

Combes, S. A., Rundle, D., IwASAKI, J. \& CRALl, J. D. (2012). Linking biomechanics and ecology through predator-prey interactions: flight performance of dragonflies and their prey. Journal of Experimental Biology 215, 903-913.

CORBET, S. A. (2000). Butterfly nectaring flowers: butterfly morphology and flower form. Entomologia Experimentalis et Applicata 96, 289-298.

Costanzo, K. \& Monteiro, A. (2007). The use of chemical and visual cues in female choice in the butterfly Bicyclus anynana. Proceedings of the Royal Society of London B: Biological Sciences 274, 845-851. 
Crall, J. D., Ravi, S., Mountcastle, A. M. \& Combes, S. A. (2015). Bumblebee flight performance in cluttered environments: effects of obstacle orientation, body size and acceleration. Journal of Experimental Biology 218, 2728-2737.

Davis, A. K., ChI, J., Bradley, C. \& Altizer, S. (2012). The redder the better: wing color predicts flight performance in monarch butterflies. PloS One 7, e41323.

Debat, V., BéAgin, M., Legout, H. \& David, J. R. (2003). Allometric and nonallometric components of Drosophila wing shape respond differently to developmental temperature. Evolution 57, 2773-2784.

Debat, V., Berthier, S., Blandin, P., Chazot, N., Elias, M., Gomez, D. \& Llaurens, V. (2018). Why are Morpho Blue? In Biodiversity and Evolution, pp. 139-174. Elsevier.

DEINERT, E. (2003). Mate location and competition for mates in a pupal mating butterfly. In: Butterflies: ecology and evolution taking flight. pp. 91-110. University of Chicago Press, Chicago.

Dell, A. I., Bender, J. A., Branson, K., Couzin, I. D., De Polavieja, G. G., Noldus, L. P. J. J. et al. (2014). Automated image-based tracking and its application in ecology. Trends in Ecology \& Evolution 29, 417-428.

DeMPSTER, J., KING, M. \& LAKHANI, K. (1976). The status of the swallowtail butterfly in Britain. Ecological Entomology 1, 71-84.

DEVRIES, P. (2002). Differential wing toughness in distasteful and palatable butterflies: direct evidence supports unpalatable theory 1 . Biotropica 34, 176-181.

DEVRIES, P. (2003). Tough African models and weak mimics: new horizons in the evolution of bad taste. Journal of Lepidopterists Society 57, 235-238.

DEVRIES, P. J. (1987). The butterflies of Costa Rica and their natural history. Volume I: Papilionidae, Pieridae, Nymphalidae. Princeton, NJ: Princeton University Press.

DeVries, P. J., Penz, C. M. \& Hill, R. I. (2010). Vertical distribution, flight behaviour and evolution of wing morphology in Morpho butterflies. Journal of animal ecology 79, 1077-1085

Devries, P. J. \& WALlA, T. R. (2001). Species diversity and community structure in neotropical fruit- feeding butterflies. Biological Journal of the Linnean Society 74, 115.

Dingle, H. (2009). Migration. In Encyclopedia of Insects (Second Edition), pp. 628-633. Elsevier.

DockX, C. (2007). Directional and stabilizing selection on wing size and shape in migrant and resident monarch butterflies, Danaus plexippus (L.), in Cuba. Biological Journal of the Linnean Society 92, 605-616.

Douwes, P. (1976). Activity in Heodes virgaureae (Lep., Lycaenidae) in relation to air temperature, solar radiation, and time of day. Oecologia 22, 287-298.

Ducatez, S., BaguetTe, M., Trochet, A., Chaput-Bardy, A., Legrand, D., Stevens, V. M. \& FreviLle, H. (2013). Flight endurance and heating rate vary with both latitude and habitat connectivity in a butterfly species. Oikos 122, 601-611.

Dudley, R. (1990). Biomechanics of flight in neotropical butterflies: morphometrics and kinematics. Journal of Experimental Biology 150, 37-53.

Dudley, R. (1991). Biomechanics of flight in neotropical butterflies: aerodynamics and mechanical power requirements. Journal of Experimental Biology 159, 335-357.

DudLey, R. (2002). The biomechanics of insect flight: form, function, evolution. Princeton University Press.

Dudley, R., Byrnes, G., Yanoviak, S. P., Borrell, B., Brown, R. M. \& McGuire, J. A. (2007). Gliding and the functional origins of flight: biomechanical novelty or necessity? Annu. Rev. Ecol. Evol. Syst. 38, 179-201.

DudLEY, R. \& SRYGLEY, R. (1994). Flight physiology of neotropical butterflies: allometry of 
airspeeds during natural free flight. Journal of Experimental Biology 191, 125-139.

Ellington, C. (1984a). The aerodynamics of hovering insect flight. I. The quasi-steady analysis. Philosophical Transactions of the Royal Society of London B: Biological Sciences 305, 1-15.

ELLington, C. (1984b). The aerodynamics of hovering insect flight. II. Morphological Parameters. Philosophical Transactions of the Royal Society of London B: Biological Sciences 305, 17-40.

Ellington, C. $(1984 c)$. The aerodynamics of hovering insect flight. III. Kinematics. Philosophical Transactions of the Royal Society of London B: Biological Sciences 305, 41-78.

ElLington, C. (1984d). The aerodynamics of hovering insect flight. IV. Aeorodynamic mechanisms. Philosophical Transactions of the Royal Society of London B: Biological Sciences 305, 79-113.

ELLINGTON, C. (1984e). The aerodynamics of hovering insect flight. VI. Lift and power requirements. Philosophical Transactions of the Royal Society B: Biological Sciences 305, 145-181.

ELLINGTON, C. P. (1984f). The aerodynamics of flapping animal flight. American Zoologist 24, 95-105.

Ellington, C. P., Van Den Berg, C., Willmott, A. P. \& Thomas, A. L. (1996). Leadingedge vortices in insect flight. Nature 384, 626.

EnNOS, A. R. (1989). The effect of size on the optimal shapes of gliding insects and seeds. Journal of Zoology 219, 61-69.

Espeland, M., Breinholt, J., Willmott, K. R., Warren, A. D., Vila, R., Toussaint, E. F., Maunsell, S. C., Aduse-Poku, K., Talavera, G. \& Eastwood, R. (2018). A comprehensive and dated phylogenomic analysis of butterflies. Current Biology 28, 770-778. e5.

Estrada, C., Yildizhan, S., Schulz, S. \& GilBert, L. E. (2010). Sex-specific chemical cues from immatures facilitate the evolution of mate guarding in Heliconius butterflies. Proceedings of the Royal Society of London B: Biological Sciences 277, 407-413.

FERNÁNDEZ, M. J., DRIVER, M. E. \& HEDRICK, T. L. (2017). Asymmetry costs: effects of wing damage on hovering flight performance in the hawkmoth Manduca sexta. Journal of Experimental Biology, jeb. 153494.

FERnÁndeZ, M. J., SpRingthorpe, D. \& Hedrick, T. L. (2012). Neuromuscular and biomechanical compensation for wing asymmetry in insect hovering flight. Journal of Experimental Biology, jeb. 073627.

Floreano, D. \& WoOD, R. J. (2015). Science, technology and the future of small autonomous drones. Nature 521, 460.

Fraimout, A., Jacquemart, P., Villarroel, B., Aponte, D. J., Decamps, T., Herrel, A., CoRnette, R. \& DeBAT, V. (2018). Phenotypic plasticity of Drosophila suzukii wing to developmental temperature: implications for flight. Journal of Experimental Biology 221, jeb166868.

Freitas, A. V., Benson, W. W., Marini-Filho, O. J. \& De Carvalho, R. M. (1997). Territoriality by the dawn's early light: the Neotropical owl butterfly Caligo idomenaeus (Nymphalidae: Brassolinae). Journal of Research on the Lepidoptera 34, $14-20$.

GARLAND, JR T. \& LOSOS, J. B. (1994). Ecological morphology of locomotor performance in squamate reptiles. In Ecological morphology: Integrative organismal biology (eds P. WAINWRIGHT and S. ReILlY), pp. 240-302. University of Chicago Press, Chicago.

Ghiradella, H., Aneshansley, D., Eisner, T., Silberglied, R. E. \& Hinton, H. E. (1972). Ultraviolet reflection of a male butterfly: interference color caused by thin-layer 
elaboration of wing scales. Science 178, 1214-1217.

GiBo, D. L. \& PALletT, M. J. (1979). Soaring flight of monarch butterflies, Danaus plexippus (Lepidoptera: Danaidae), during the late summer migration in southern Ontario. Canadian Journal of Zoology 57, 1393-1401.

GILCHRIST, G. (1990). The consequences of sexual dimorphism in body size for butterfly flight and thermoregulation. Functional Ecology 4, 475-487.

GRODNITSKII, D. \& KozLOV, M. (1985). Functional morphology of the wing apparatus and flight peculiarities in primitive moths (Lepidoptera: Micropterigidae, Eriocraniidae). Zoologicheskii zhurnal 64, 1661-71. (In Russian)

HAILS, C. (1979). A comparison of flight energetics in hirundines and other birds. Comparative Biochemistry and Physiology Part A: Physiology 63, 581-585.

Hall, J. P. \& WiLlmotT, K. R. (1979). Patterns of feeding behavior in adult male riodinid butterflies and their relationship to morphology and ecology. Biological Journal of the Linnean Society 69, 1-23.

Hedenström, A. \& Møller, A. (1992). Morphological adaptations to song flight in passerine birds: a comparative study. Proceedings of the Royal Society of London Series B 247, 183-187.

HEDRICK, T. L. (2008). Software techniques for two-and three-dimensional kinematic measurements of biological and biomimetic systems. Bioinspiration \& biomimetics $\mathbf{3}$, 034001.

Hernández, L N., Barragán, A., Dupas, S., Silvain, J.-F. \& Dangles, O. (2010). Wing shape variations in an invasive moth are related to sexual dimorphism and altitude. Bulletin of entomological research 100, 529--541.

Hill, J. K. \& Gatehouse, A. G. (1993). Phenotypic plasticity and geographical variation in the pre-reproductive period of Autographa gamma (Lepidoptera: Noctuidae) and its implications for migration in this species. Ecological Entomology 18, 39-46.

Holland, R. A., Wikelski, M. \& Wilcove, D. S. (2006). How and why do insects migrate? Science 313, 794-796.

Hughes, C. L., Hill, J. K. \& Dytham, C. (2003). Evolutionary trade-offs between reproduction and dispersal in populations at expanding range boundaries. Proceedings of the Royal Society of London B: Biological Sciences 270, S147-S150.

Humphries, D. \& Driver, P. (1970). Protean defence by prey animals. Oecologia 5, 285-302.

IDE, J.-Y. (2006). Sexual and seasonal differences in the frequency of beak marks on the wings of two Lethe butterflies. Ecological Research 21, 453-459.

IMAFUKU, M. \& OHTANI, T. (2006). Analysis of coordinated circling and linear flights of a lycaenid butterfly species. Naturwissenschaften 93, 131-135.

Jackson, B. E., Evangelista, D. J., RAY, D. D. \& HedRicK, T. L. (2016). 3D for the people: multi-camera motion capture in the field with consumer-grade cameras and open source software. Biology open 5, 1334-1342.

JANTZEN, B. \& EISNER, T. (2008). Hindwings are unnecessary for flight but essential for execution of normal evasive flight in Lepidoptera. Proceedings of the National Academy of Sciences 105, 16636-16640.

JohANSSON, F., SÖDERQUist, M. \& BOKMA, F. (2009). Insect wing shape evolution: independent effects of migratory and mate guarding flight on dragonfly wings. Biological Journal of the Linnean Society 97, 362-372.

Jones, R. T., Poul, Y. L., Whibley, A. C., Mérot, C. \& Joron, M. (2013). Wing shape variation associated with mimicry in butterflies. Evolution 67, 2323-2334.

KARLSSON, B. \& WiCKMAN, P.-O. (1990). Increase in reproductive effort as explained by body size and resource allocation in the speckled wood butterfly, Pararge aegeria (L.). Functional ecology 4, 609-617. 
KATO, Y. \& YOSHIOKA, Y. (2003). Visual stimuli affecting male mating behavior of Graphium sarpedon (Lepidoptera, Papilionidae). Lepidoptera Science 54, 209-219.

KEMP, D. J. (2007). Female butterflies prefer males bearing bright iridescent ornamentation. Proceedings of the Royal Society of London B: Biological Sciences 274, 1043-1047.

KeMP, D. J. (2013). Contest behaviour in butterflies: fighting without weapons. In Animal Contests (eds I. C. W. HARDY \& M. BRIFFA), pp. 134-146. Cambridge University Press, Cambridge.

Kingsolver, J. G. (1983). Thermoregulation and flight in Colias butterflies: elevational patterns and mechanistic limitations. Ecology 64, 534-545.

Kingsolver, J. G. \& Huey, R. B. (2003). Introduction: the evolution of morphology, performance, and fitness. Integrative and comparative biology 43, 361-366.

Kingsolver, J. G. \& KoeHL, M. (1985). Aerodynamics, thermoregulation, and the evolution of insect wings: differential scaling and evolutionary change. Evolution 39, 488-504.

KitAMURA, T. \& IMAfUKU, M. (2015). Behavioural mimicry in flight path of Batesian intraspecific polymorphic butterfly Papilio polytes. Proceedings of the Royal Society of London Series B 282, 20150483.

KLINGENBERG, C. P. (2010). Evolution and development of shape: integrating quantitative approaches. Nature Reviews Genetics 11, 623.

KLingenBerG, C. P. (2011). MorphoJ: an integrated software package for geometric morphometrics. Molecular ecology resources 11, 353-357.

Koskinen, M. T., Haugen, T. O. \& Primmer, C. R. (2002). Contemporary fisherian lifehistory evolution in small salmonid populations. Nature 419, 826.

Kristensen, N. P., Scoble, M. J. \& Karsholt, O. (2007). Lepidoptera phylogeny and systematics: the state of inventorying moth and butterfly diversity. Zootaxa 1668, e747.

Kruijt, B., Malhi, Y., Lloyd, J., Norbre, A., Miranda, A., Pereira, M., Culf, A. \& GRACE, J. (2000). Turbulence statistics above and within two Amazon rain forest canopies. Boundary-Layer Meteorology 94, 297-331.

Leinonen, T., MCCairns, R. S., O'Hara, R. B. \& Merilä, J. (2013). Q ST-F ST comparisons: evolutionary and ecological insights from genomic heterogeneity. Nature Reviews Genetics 14, 179.

LENTINK, D. \& DE KAT, R. (2014). Gliding swifts attain laminar flow over rough wings. PLoS One 9, e99901.

Lentink, D., Müller, U., Stamhuis, E., De Kat, R., Van Gestel, W., Veldhuis, L., Henningsson, P., Hedenström, A., Videler, J. J. \& Van Leeuwen, J. L. (2007). How swifts control their glide performance with morphing wings. Nature 446, 1082.

LIU, H. \& KAWACHI, K. (1998). A numerical study of insect flight. Journal of Computational Physics 146, 124-156.

LiU, H., RaVi, S., KolomenskiY, D. \& TANAKA, H. (2016). Biomechanics and biomimetics in insect-inspired flight systems. Philosophical Transactions of the Royal Society of London Series B 371, 20150390.

LOCKWOOD, R., SWADDLE, J. P. \& RAYNER, J. M. (1998). Avian wingtip shape reconsidered: wingtip shape indices and morphological adaptations to migration. Journal of Avian Biology 29, 273-292.

LÓPEZ-PALAFOX, T. G. \& Cordero, C. R. (2017). Two-headed butterfly vs. mantis: do false antennae matter? PeerJ 5, e3493.

LóPez-PALAFOX, T. G., Luis-MARTínez, A. \& Cordero, C. (2015). The movement of "false antennae" in butterflies with "false head" wing patterns. Current Zoology 61, 758764.

Losos, J. B., Creer, D. A. \& Schulte II, J. A. (2002). Cautionary comments on the 
measurement of maximum locomotor capabilities. Journal of Zoology 258, 57-61.

Magnan, A. (1934). La locomotion chez les animaux. Hermann \& cie.

MAgnus, D. (1950). Beobachtungen zur Balz und Eiablage des Kaisermantels Argynnis paphia L.(Lep., Nymphalidae) 1. Zeitschrift für Tierpsychologie 7, 435-449.

MARDEN, J. H. \& CHAI, P. (1991). Aerial predation and butterfly design: how palatability, mimicry, and the need for evasive flight constrain mass allocation. American Naturalist 138, 15-36.

MendozA-CuencA, L. \& Macías-OrdóÑez, R. (2005). Foraging polymorphism in Heliconius charitonia (Lepidoptera: Nymphalidae): morphological constraints and behavioural compensation. Journal of Tropical Ecology 21, 407-415.

MendozA-Cuenta, L. F. (2004). Mating strategies in Heliconius charitonia (Lepidoptera: Nymphalidae): factors involved in pupal mating evolution. Ph.D. Dissertation, Instituto de Ecologia A. C.

Merrill, R. M., Dasmahapatra, K. K., Davey, J. W., Dell'Aglio, D., Hanly, J., Huber, B., Jiggins, C. D., Joron, M., KozAK, K. \& Llaurens, V. (2015). The diversification of Heliconius butterflies: what have we learned in 150 years? Journal of evolutionary biology 28, 1417-1438.

Mountcastle, A. M. \& Daniel, T. L. (2010). Aerodynamic and functional consequences of wing compliance. In Animal Locomotion, pp. 311-320. Springer.

MuHAMAD, O., TsUKUdA, R., OKI, Y., FUJISAKI, K. \& NAKASUJI, F. (1994). Influences of wild crucifers on life history traits and flight ability of the diamondback moth, Plutella xylostella (Lepidoptera: Yponomeutidae). Researches on population ecology 36, 53.

Muijres, F. T., Iwasaki, N. A., Elzinga, M. J., Melis, J. M. \& DiCKinson, M. H. (2017). Flies compensate for unilateral wing damage through modular adjustments of wing and body kinematics. Interface Focus 7, 20160103.

MÜLlER, F. (1879). Ituna and Thyridia: a remarkable case of mimicry in butterflies. Trans. Entomol. Soc. Lond 1879, 20-29.

Nittepõld, K., Mattila, A. L., Harrison, P. J. \& HANSKI, I. (2011). Flight metabolic rate has contrasting effects on dispersal in the two sexes of the Glanville fritillary butterfly. Oecologia 165, 847-854.

NiJHout, H. F. (1991). The development and evolution of butterfly wing patterns. Smithsonian Institution Press, Washington, DC.

NisHIDA, R. (2002). Sequestration of defensive substances from plants by Lepidoptera. Annual review of entomology 47, 57-92.

Norberg, U. (1990). Vertebrate Flight: Mechanics, Physiology, Morphology, Ecology, and Evolution. Springer.

NoRberG, U. M. (1994). Wing design, flight performance, and habitat use in bats. In Ecological morphology: Integrative organismal biology (eds P. WAINWRIGHT and S. REILLY), pp. 205-239. University of Chicago Press, Chicago.

NorberG, U. M. (2002). Structure, form, and function of flight in engineering and the living world. Journal of morphology 252, 52-81.

NoRBERG, U. M. (2012). Vertebrate flight: mechanics, physiology, morphology, ecology and evolution. Springer Science \& Business Media.

NorberG, U. M. \& RAYNeR, J. M. (1987). Ecological morphology and flight in bats (Mammalia; Chiroptera): wing adaptations, flight performance, foraging strategy and echolocation. Philosophical Transactions of the Royal Society B: Biological Sciences 316, 335-427.

OHSAKI, N. (1995). Preferential predation of female butterflies and the evolution of Batesian mimicry. Nature 378, 173.

Ortega-Jimenez, V. M., Greeter, J. S., Mittal, R. \& Hedrick, T. L. (2013). Hawkmoth 
flight stability in turbulent vortex streets. Journal of Experimental Biology, jeb. 089672.

Outomuro, D., Adams, D. C. \& Johansson, F. (2013a). Wing shape allometry and aerodynamics in calopterygid damselflies: a comparative approach. BMC evolutionary biology 13, 118.

Outomuro, D., Dijkstra, K. D. \& Johansson, F. (2013b). Habitat variation and wing coloration affect wing shape evolution in dragonflies. Journal of evolutionary biology 26, 1866-1874.

OutOMURo, D. \& JohAnsson, F. (2015). Bird predation selects for wing shape and coloration in a damselfly. Journal of evolutionary biology 28, 791-799.

Outomuro, D., Söderquist, L., Nilsson- Örtman, V., Cortázar- Chinarro, M., LUNDGREN, C. \& JOHANSSON, F. (2016). Antagonistic natural and sexual selection on wing shape in a scrambling damselfly. Evolution 70, 1582-1595.

PARK, H., BAE, K., LeE, B., JeON, W.-P. \& CHOI, H. (2010). Aerodynamic performance of a gliding swallowtail butterfly wing model. Experimental Mechanics 50, 1313-1321.

Pellegroms, B., Van Dongen, S., VAn DycK, H. \& Lens, L. (2009). Larval food stress differentially affects flight morphology in male and female speckled woods (Pararge aegeria). Ecological Entomology 34, 387-393.

PenNyCUiCK, C. (1975). Mechanics of flight. Avian biology 5, 1-75.

PenZ, C. \& Heine, K. (2016). Did adult diurnal activity influence the evolution of wing morphology in Opoptera butterflies? Neotropical entomology 45, 50-57.

Penz, C. M. \& DeVRIES, P. J. (2002). Phylogenetic analysis of Morpho butterflies (Nymphalidae, Morphinae): implications for classification and natural history. American Museum Novitates 3374, 1-33.

Percin, M., Hu, Y., Van Oudheusden, B., Remes, B. \& Scarano, F. (2011). Wing flexibility effects in clap-and-fling. International Journal of Micro Air Vehicles 3, 217-227.

PINHEIRO, C. E. (1996). Palatablility and escaping ability in Neotropical butterflies: tests with wild kingbirds (Tyrannus melancholicus, Tyrannidae). Biological Journal of the Linnean Society 59, 351-365.

Ray, R. P., Nakata, T., Henningsson, P. \& Bomphrey, R. J. (2016). Enhanced flight performance by genetic manipulation of wing shape in Drosophila. Nature communications 7, 10851.

RAYNeR, J. M. (1988). Form and function in avian flight. Current ornithology 5, 1-66.

RAYNER, J. M. (1991). On the aerodynamics of animal flight in ground effect. Philosophical Transactions of the Royal Society of London B: Biological Sciences 334, 119-128.

ReIM, E., Blesinger, S., FÖRSTER, L. \& Fischer, K. (2018). Successful despite poor flight performance: range expansion is associated with enhanced exploratory behaviour and fast development. Journal of evolutionary biology 1, 1165-1179.

Ricklefs, R. E., KonARzewsKi, M. \& DAAN, S. (1996). The relationship between basal metabolic rate and daily energy expenditure in birds and mammals. The American Naturalist 147, 1047-1071.

RoBbins, R. K. (1980). The Lycaenid false head hypothesis: historical review and quantitative analysis [Lepidoptera]. Journal of the Lepidopterists' Society (USA) 34, 194-208.

RoBbins, R. K. (1981). The" false head" hypothesis: predation and wing pattern variation of lycaenid butterflies. The American Naturalist 118, 770-775.

Robertson, K. A. \& Monteiro, A. (2005). Female Bicyclus anynana butterflies choose males on the basis of their dorsal UV-reflective eyespot pupils. Proceedings of the Royal Society of London B: Biological Sciences 272, 1541-1546.

RofF, D. A. \& FAIRBAIRN, D. J. (2007). The evolution and genetics of migration in insects. 
AIBS Bulletin 57, 155-164.

RoHLF, F. J. (2015). The tps series of software. Hystrix 26, 1-4.

ROHLF, F. J. \& MARCUS, L. F. (1993). A revolution in morphometrics. Trends in ecology and evolution 8, 129-129.

Rubin, J. J., Hamilton, C. A., McClure, C. J., Chadwell, B. A., Kawahara, A. Y. \& BARBER, J. R. (2018). The evolution of anti-bat sensory illusions in moths. Science Advances 4, eaar7428.

RutowsKi, R. L. (1991). The evolution of male mate-locating behavior in butterflies. The American Naturalist 138, 1121-1139.

SÁfIÁN, S. (2013). Observation of hill-topping behaviour by the Giant African SwallowtailPapilio antimachus Drury, 1782 and other recent records from Liberia (West Africa) (Lepidoptera: Papilionidae). SHILAP Revista de Lepidopterología 41, 323-329.

SANE, S. P. (2003). The aerodynamics of insect flight. Journal of Experimental Biology 206, 4191-4208.

SANE, S. P. \& Dickinson, M. H. (2002). The aerodynamic effects of wing rotation and a revised quasi-steady model of flapping flight. Journal of Experimental Biology 205, 1087-1096.

Schäfer, M. A., Berger, D., Rohner, P. T., Kuaerggaard, A., Bauerfeind, S. S., Guillaume, F., FoX, C. W. \& Blanckenhorn, W. U. (2018). Geographic in wing morphology relate to colonization history in New World but not Old World populations of yellow dung flies. Evolution 72, 1629-1644.

ScotT, J. A. (1973). Mating of butterflies. Journal of Research on the Lepidoptera 11, 99127.

ScotT, J. A. (1974). Mate-locating behavior of butterflies. American Midland Naturalist 91, 103-117.

Shelton, R. M., Jackson, B. E. \& HedRICK, T. L. (2014). The mechanics and behavior of cliff swallows during tandem flights. Journal of Experimental Biology 217, 27172725.

SherratT, T. N. \& BEATTY, C. D. (2003). The evolution of warning signals as reliable indicators of prey defense. The American Naturalist 162, 377-389.

SHREEVE, T. (1984). Habitat selection, mate location, and microclimatic constraints on the activity of the speckled wood butterfly Pararge aegeria. Oikos 42, 371-377.

SHREEVE, T. (1987). The mate location behaviour of the male speckled wood butterfly, Pararge aegeria, and the effect of phenotypic differences in hind-wing spotting. Animal Behaviour 35, 682-690.

SHREEVE, T. (1992). Adult behaviour. The ecology of butterflies in Britain. Oxford University Press, Oxford, 22-45.

SRIDHAR, M. K., KANG, C.-K. \& LANDRUM, D. B. (2016). Instantaneous lift and motion characteristics of butterflies in free flight. In 46th AIAA Fluid Dynamics Conference, pp. 3252.

SRYGLEY, R. B. (1994). Locomotor mimicry in butterflies? The associations of positions of centres of mass among groups of mimetic, unprofitable prey. Philosophical Transactions of the Royal Society of London B: Biological Sciences 343, 145-155.

SRYGLEY, R. B. (1999). Locomotor mimicry in Heliconius butterflies: contrast analyses of flight morphology and kinematics. Philosophical Transactions of the Royal Society of London B: Biological Sciences 354, 203-214.

SRYGLEY, R. B. (2004). The aerodynamic costs of warning signals in palatable mimetic butterflies and their distasteful models. Proceedings of the Royal Society of London B: Biological Sciences 271, 589-594.

SRYGLey, R. B. \& CHAI, P. (1990). Predation and the elevation of thoracic temperature in 
brightly colored Neotropical butterflies. American Naturalist 135, 766-787.

SRYGley, R. B. \& Dudley, R. (1993). Correlations of the position of center of body mass with butterfly escape tactics. Journal of Experimental Biology 174, 155-166.

SRYGLEY, R. B. \& ElLington, C. (1999). Discrimination of flying mimetic, passion-vine butterflies Heliconius. Proceedings of the Royal Society of London B: Biological Sciences 266, 2137-2140.

SRYGLEY, R. \& THOMAS, A. (2002). Unconventional lift-generating mechanisms in free-flying butterflies. Nature 420, 660-664.

Stevenson, R., Corbo, K., BacA, L. \& Le, Q. (1995). Cage size and flight speed of the tobacco hawkmoth Manduca sexta. Journal of Experimental Biology 198, 1665-1672.

SuzUKI, T. K., TOMITA, S. \& SEzUTSU, H. (2014). Gradual and contingent evolutionary emergence of leaf mimicry in butterfly wing patterns. BMC Evolutionary Biology 14, 1.

TAKEUCHI, T. (2017). Agonistic display or courtship behavior? A review of contests over mating opportunity in butterflies. Journal of ethology 35, 3-12.

TANAlgo, K. C., Achondo, M. J. M. M., BRetañA, B. L. P., CAsim, L. F. \& TABORA, J. A. G. (2012). Wing ecomorphology and flight performance of bats in Pisan Caves, Kabacan, North Cotabato, Philippines. Asian Journal of Biodiversity 3, 113-125.

Tercel, M. P., Veronesi, F. \& Pope, T. W. (2018). Phylogenetic clustering of wingbeat frequency and flight- associated morphometrics across insect orders. Physiological Entomology 43, 149-157.

Theriault, D. H., Fuller, N. W., Jackson, B. E., Bluhm, E., Evangelista, D., Wu, Z., BETKE, M. \& HEDRICK, T. L. (2014). A protocol and calibration method for accurate multi-camera field videography. Journal of Experimental Biology, jeb. 100529.

Thomas, A. L. \& BAlmFord, A. (1995). How natural selection shapes birds' tails. The American Naturalist 146, 848-868.

TILlyard, R. J. (1918). The panorpoid complex. Part i. The wing-coupling apparatus, with special reference to the Lepidoptera. Proc. Linn. Soc. NSW 43, 286-319.

Tinbergen, N., Meeuse, B. \& Varossieau, L. B. U. W. (1942). Die Balz des Samtfalters, Eumenis (= Satyrus) semele (L.). Zeitschrift für Tierpsychologie 5, 182-226.

VAn Dyck, H., Matthysen, E. \& DhONDT, A. (1997). Mate- locating strategies are related to relative body length and wing colour in the speckled wood butterfly Pararge aegeria. Ecological Entomology 22, 116-120.

VAnce, J. T. \& RoBerTS, S. P. (2014). The effects of artificial wing wear on the flight capacity of the honey bee Apis mellifera. Journal of insect physiology 65, 27-36.

VoGeL, S. (1994). Life in moving fluids: the physical biology of flow. Princeton University Press.

Volponi, M. A. S., McLEAN, D. J., VolPoni, P. \& DudLEy, R. (2018). Moving like a model: mimicry of hymenopteran flight trajectories by clearwing moths of Southeast Asian rainforests. Biology letters 14, 20180152.

VuKusic, P., SAMBles, J. \& LAWRENCE, C. (2000). Structural colour: colour mixing in wing scales of a butterfly. Nature 404, 457.

WAINWRIGHT, P. C. (1991). Ecomorphology: experimental functional anatomy for ecological problems. American Zoologist 31, 680-693.

WAINWRIGHT, P. C. \& REILLY, S. M. (1994). Ecological morphology: integrative organismal biology. University of Chicago Press.

WALlace, A. (1865). On the phenomena of variation and geographical distribution as illustrated by the Papilionidae of the Malayan region. Linnean Society of London Transactions 25: 1-71+ 8 plates. Partly reprinted: Pages 314-316 in CH Smith, editor. 1991. Alfred Russel Wallace: an anthology of his shorter writings. Online: see 
Wallace.

WANG, Z. J. (2005). Dissecting insect flight. Annu. Rev. Fluid Mech. 37, 183-210.

WASSERTHAL, L. T. (1975). The role of butterfly wings in regulation of body temperature. Journal of insect physiology 21, 1921-1930.

WeIs-FoGH, T. (1956). Biology and physics of locust flight II. Flight performance of the desert locust (Schistocerca gregaria). Phil. Trans. R. Soc. Lond. B 239, 459-510.

WEIS-FOGH, T. (1973). Quick estimates of flight fitness in hovering animals, including novel mechanisms for lift production. Journal of Experimental Biology 59, 169-230.

West-Eberhard, M. J. (1989). Phenotypic plasticity and the origins of diversity. Annual review of Ecology and Systematics 20, 249-278.

WiCKMAN, P.-O. (1992). Sexual selection and butterfly design-a comparative study. Evolution 46, 1525-1536.

WiKLunD, C. (2003). Sexual selection and the evolution of butterfly mating systems. Butterflies: ecology and evolution taking flight. University of Chicago Press, Chicago 67, 90.

WiKLund, C. \& FAGERSTRÖM, T. (1977). Why do males emerge before females? Oecologia 31, 153-158.

Williams, C. B. (1930). The migration of butterflies. The Migration of Butterflies. Oliver and Boyd, Edinburgh.

Willmott, A. P. \& Ellington, C. P. (1997a). The mechanics of flight in the hawkmoth Manduca sexta. I. Kinematics of hovering and forward flight. Journal of Experimental Biology 200, 2705-2722.

Willmott, A. P. \& Ellington, C. P. (1997b). The mechanics of flight in the hawkmoth Manduca sexta. II. Aerodynamic consequences of kinematic and morphological variation. Journal of Experimental Biology 200, 2723-2745.

Willmott, K. R., Willmott, J. C. R., Elias, M. \& Jiggins, C. D. (2017). Maintaining mimicry diversity: optimal warning colour patterns differ among microhabitats in Amazonian clearwing butterflies. Proceedings of the Royal Society of London Series $B$ 284, 20170744.

WootTon, R. J. (1981). Support and deformability in insect wings. Journal of Zoology 193, 447-468.

Wootton, R. J. (1990). The mechanical design of insect wings. Scientific American 263, 114-121.

WootTon, R. J. (1992). Functional morphology of insect wings. Annual review of entomology 37, 113-140.

Young, J., Walker, S. M., Bomphrey, R. J., TAylor, G. K. \& Thomas, A. L. (2009). Details of insect wing design and deformation enhance aerodynamic function and flight efficiency. Science 325, 1549-1552.

ZANKeR, J. \& GÖTZ, K. (1990). The wing beat of Drosophila melanogaster. II. Dynamics. Phil. Trans. R. Soc. Lond. B 327, 19-44.

Zhang, L., Martin, A., Perry, M. W., van der Burg, K. R., Matsuoka, Y., Monteiro, A. \& REED, R. D. (2017). Genetic basis of melanin pigmentation in butterfly wings. Genetics 116.196451.

Zhao, L., Deng, X. \& Sane, S. P. (2011). Modulation of leading edge vorticity and aerodynamic forces in flexible flapping wings. Bioinspiration \& biomimetics 6, 036007.

Zheng, L., Hedrick, T. L. \& MitTAL, R. (2013). Time-varying wing-twist improves aerodynamic efficiency of forward flight in butterflies. PloS one 8, e53060. 


\section{Figure legends}

Fig. 1 Relationships between morphology, performance and fitness shown in a hypothetical adaptive landscape. Each line delimitates equal fitness areas, and two fitness optima are displayed. Two populations (or species) are shown, displaying morphologies 1 and 2, respectively. Within each group, morphological variation is displayed by different bars. The associated performance is shown by the dark red line, and is achieved by extreme behavioural values. The individual behavioural range allowed by its morphology is displayed as an open bar. The pink colour gradient in each bar shows the frequency distribution of behaviours actually performed by each individual. For both populations, some morphology allows high fitness, but through contrasting behaviour; in Population 1 the fitness values are limited by the maximum performance allowed by the morphology, so that extreme behaviours allowing maximal performance would be expected to be frequent. Selection for increased performance might be constrained by physical properties of the morphology, fixing the upper performance limit. Most individuals from Population 2 reach the fitness peak, using a behaviour that does not maximize performance.

Fig. 2. (A) Aerodynamic consequences of variation in wing aspect ratio $(A R)$. Wings that are long relative to the mean wing width have a higher aspect ratio than shorter wings of equal area. At a constant velocity and orientation, wings with a high aspect ratio generate smaller wingtip vortices than low-aspect-ratio wings, limiting the energy required to generate comparable lift forces. (B) Two butterfly forewings with different moments of area. The moment of area of a wing depends on the distribution of the chord (i.e. wing width) along the wing axis and therefore varies with wing shape [see Ellington (1984b) for further details on wing moments and their formulae]. Larger wing chord is represented by darker grey shade. The more wing area is located distally relative to the wing base (symbolized as a black dot), the higher is the moment of area. During flapping flight, the distally located area moves air with a larger speed than that located more basally, and thus generate higher aerodynamic forces per unit area. Wings with a high moment of area are thus associated with more efficient flapping flight than wings with a lower moment of area.

Fig. 3. Methods used to quantify the effect of wing shape variation on flight performance in butterflies. (A) Artificial wing models allow testing aerodynamic performance associated with different wing shapes (Ancel et al., 2017). (B) Tethered-flight experiments (here for Melitaea cinxia) in laboratory conditions have been used to measure flight endurance (Niitepõld et al., 2011). (C) Vanessa atalanta flying freely in a wind tunnel. The smoke stream allows visualization of unsteady flows produced by the butterfly (Srygley \& Thomas, 2002). (D) Morpho achilles flying freely in a large insectary $(8 \mathrm{~m} \times 4 \mathrm{~m} \times 2.5 \mathrm{~m})$. The three-dimensional flight trajectory can be reconstructed by filming simultaneously with several cameras. (E) Measurement of natural flight speed of butterflies while crossing a lake (Dudley \& Srygley, 1994). Photograph credits: A, Mirko Kovak; B, Rebecca Nesbit; C, Robert Srygley and Adrian Thomas; D, Camille Le Roy; E, Marcos Guerra.

Fig. 4. Plot of aspect ratio versus second moment of area of the forewing for 168 butterfly species representing all subfamilies and $98 \%$ of all tribes. The phylogenetic tree obtained from Espeland et al. (2018) is projected into the morphospace. A large aspect ratio reflects higher gliding efficiency, while a large second moment of area is associated with better flapping efficiency. However no clear relationship between these two predictors of flight performance emerges at the macro-evolutionary scale. Data were computed using wingImageProcessor Matlab (http://www.unc.edu/ therick/) on scaled photographs of 
Fig. 5. Plot of aspect ratio $(A R)$ versus wing loading (WL) (logarithmic scales) and their association with flight speed in various butterflies. Grey shading in circles corresponds to flight speed. Unpalatable species are highlighted with a red outline: their low wing loading combined with a high aspect ratio allows slow, inexpensive flight. Conversely, high wing loading allows faster flight (regardless of aspect ratio), associated with higher energetic costs. Although this morphology may be favoured in palatable species which are more prone to predation, variation in wing loading is large among palatable butterfly species. Data obtained from Betts \& Wootton (1988) and Dudley \& Srygley (1994). Species are shown at their relative sizes.

Fig. 6. Flight speed versus wing loading (WL) for eight Neotropical butterfly species either measured in free flight over a Panamanian lake (Dudley \& Srygley, 1994), or inside an insectary (3.4 $\mathrm{m} \times 3 \mathrm{~m} \times 2.1 \mathrm{~m}$ ) (Dudley, 1990). While the speed range observed in the insectary was below that in the wild, the observed positive covariation between flight speed and wing loading found in natural flights is replicated by the insectary data. 
Figure 1

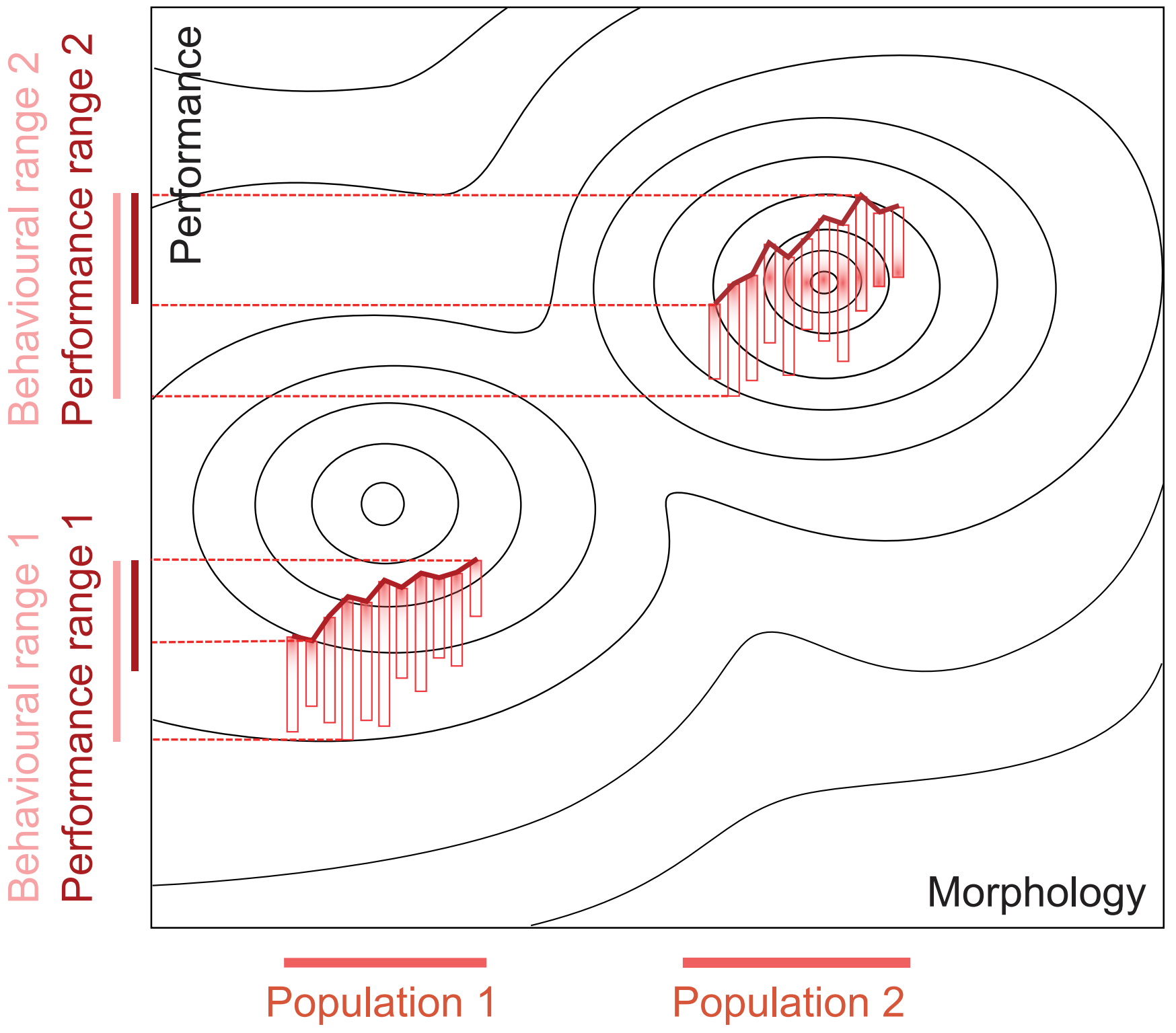


Figure 2

(A) Aspect ratio
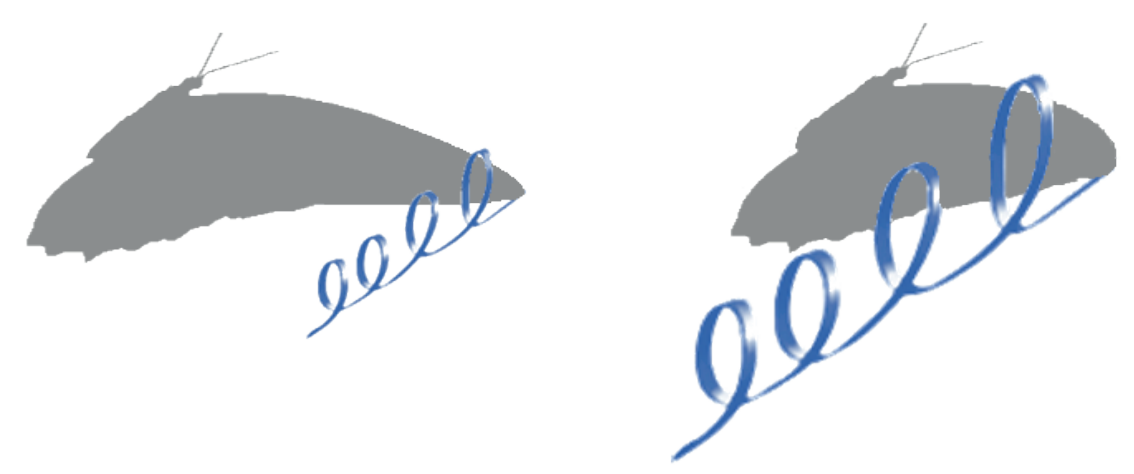

(B) Moment of area

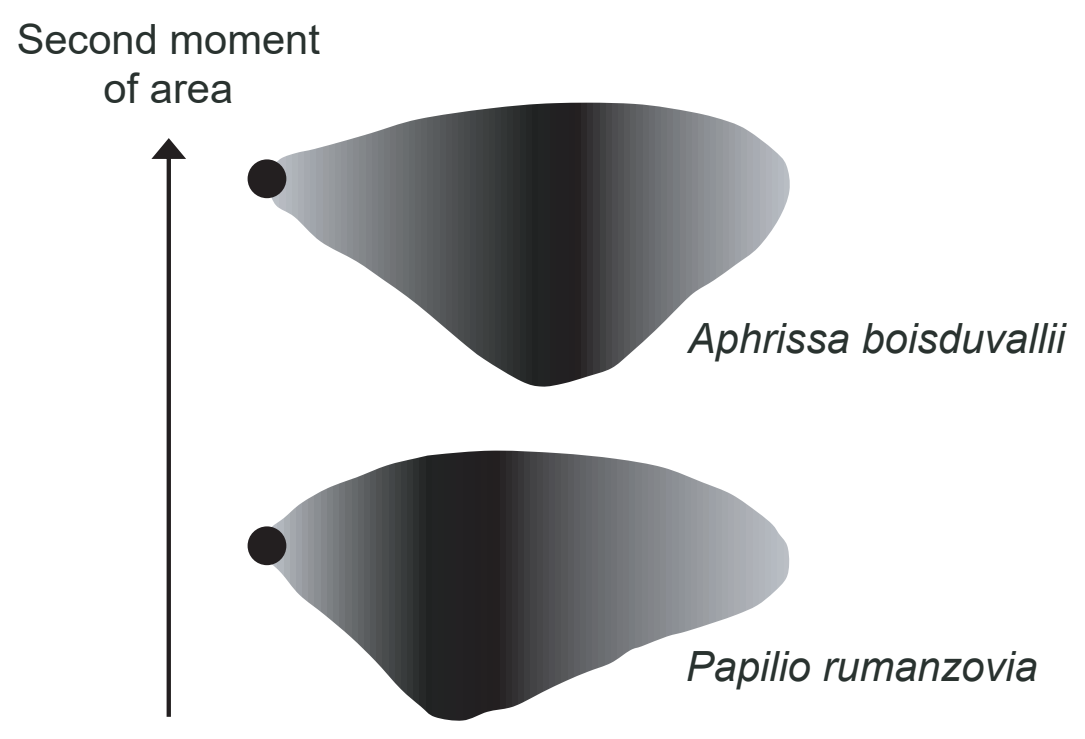


Figure 3
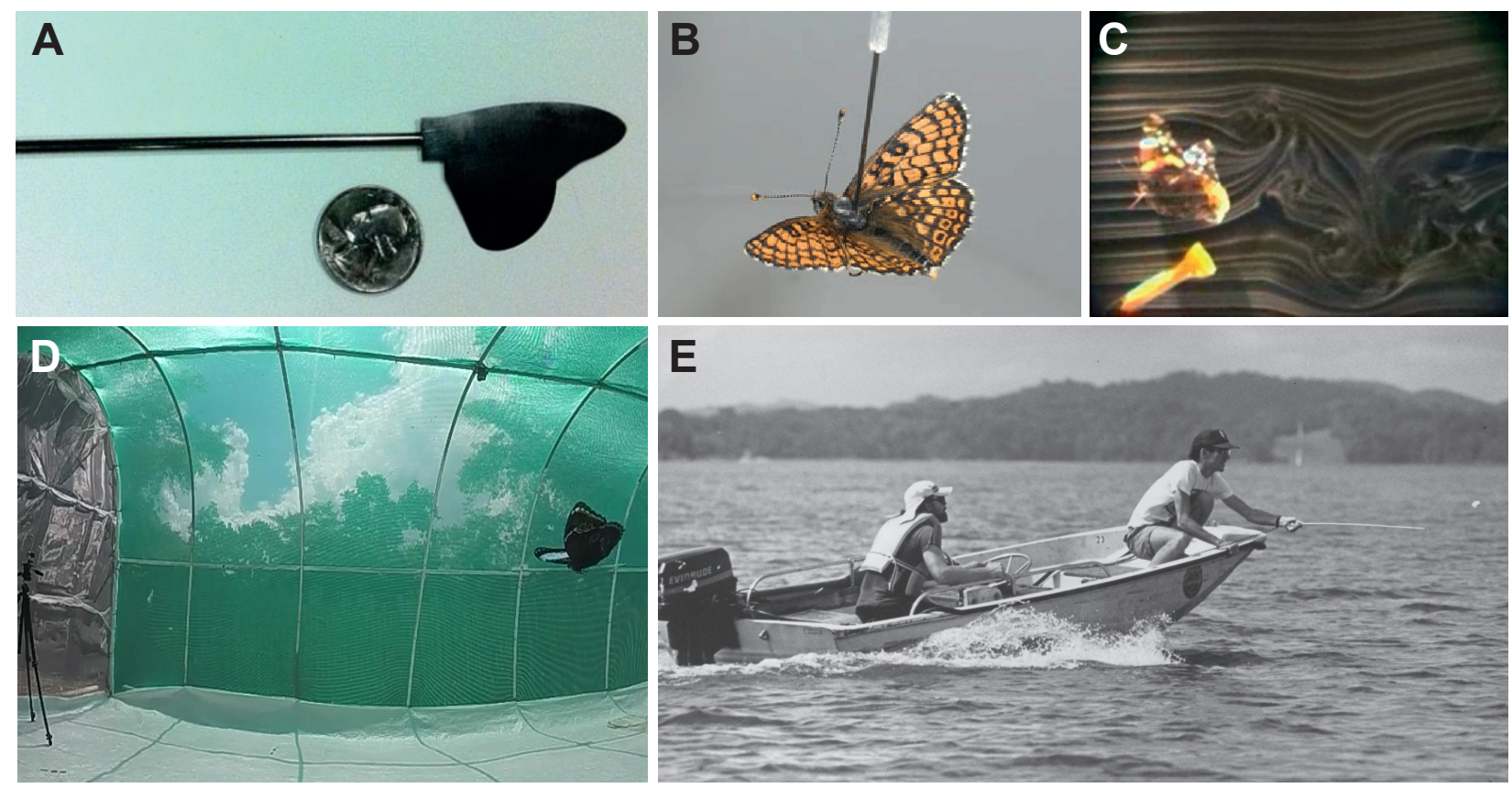
Figure 4

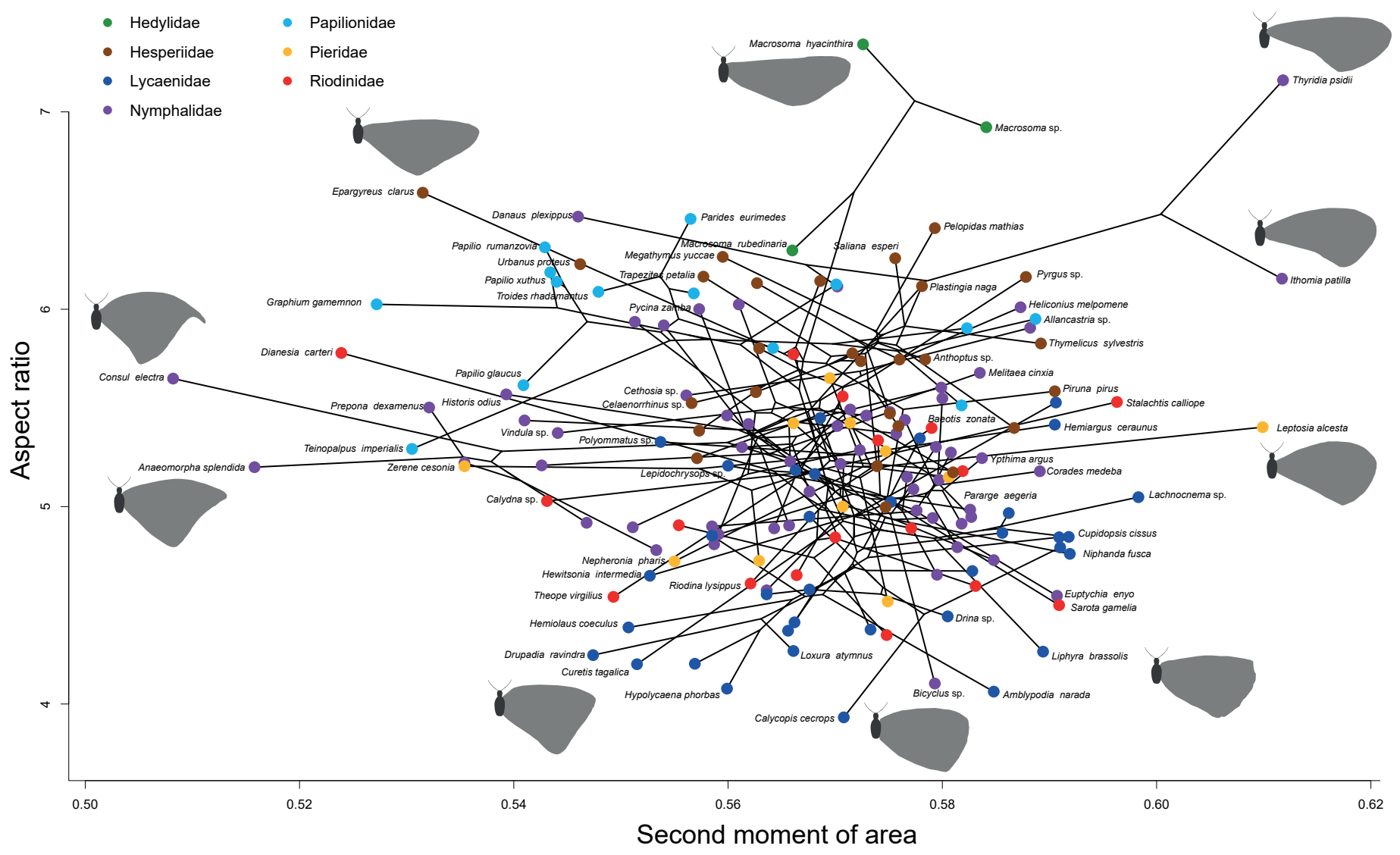


Figure 5

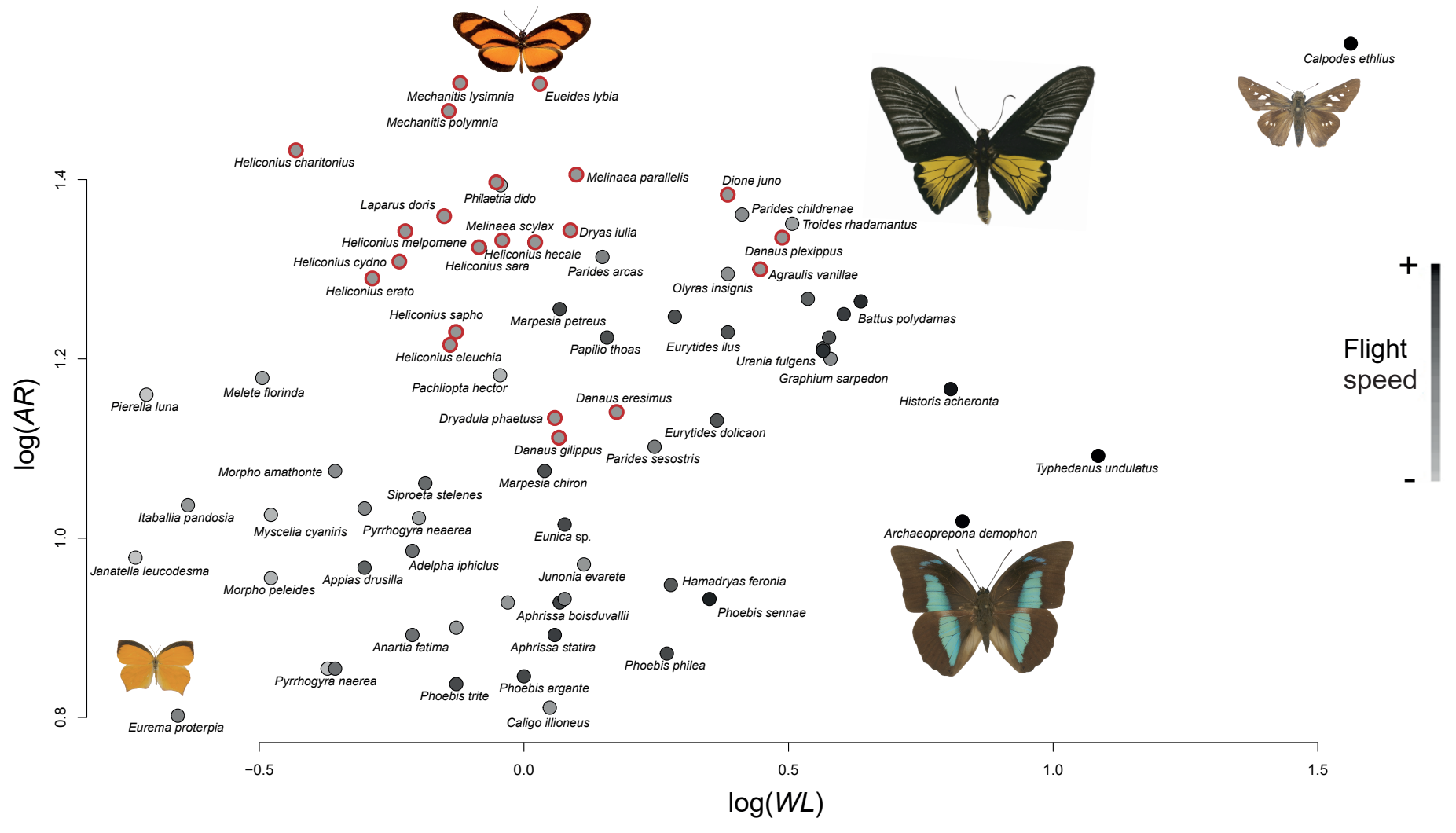


Figure 6

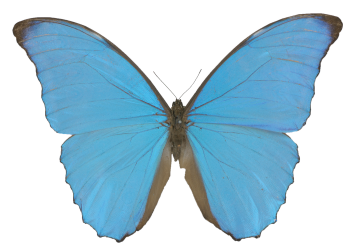

1. Morpho amathonte

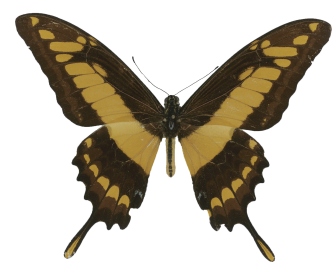

5. Papilio thoas

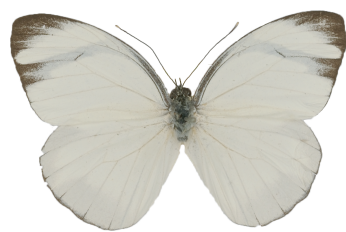

2. Itaballia demophile

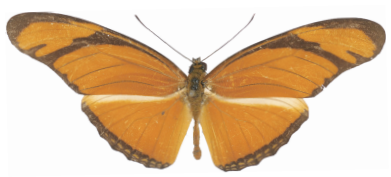

6. Dryas iulia

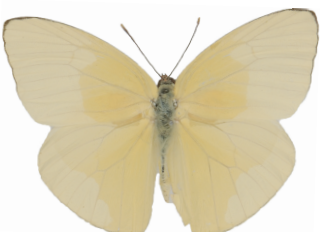

3. Aphrissa boisduvalii

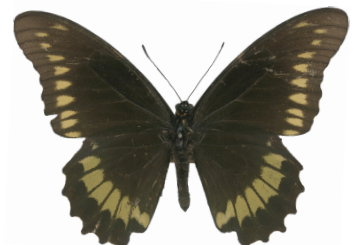

7. Battus polydamas

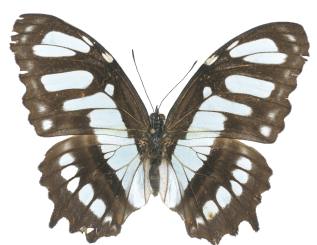

4. Siproeta stelenes

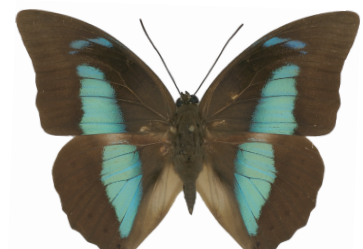

8. Archaeoprepona demophon

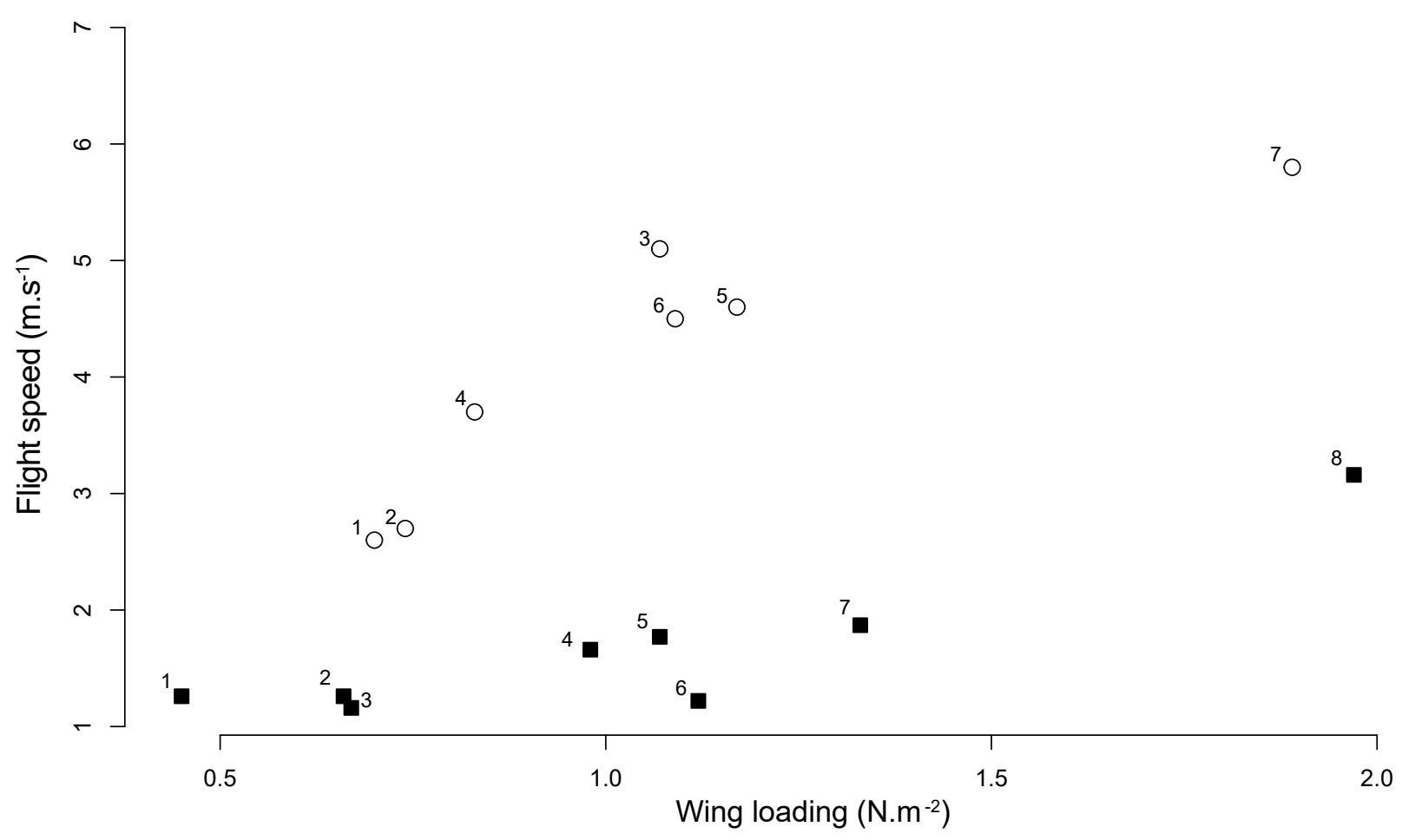

